\title{
INVESTOR RISK AVERSION AND FINANCIAL FRAGILITY IN EMERGING ECONOMIES
}

\author{
Jeffrey $H$. Nilsen \\ Studienzentrum Gerzensee and University of Bern \\ Tel. +41.31.780.3108; $\quad$ Fax +41.31.780.3100 \\ e-mail: jhn@szgerzensee.ch \\ Riccardo Rovelli \\ University of Bologna \\ Tel. +39.051.209.601; Fax +39.051.209.664 \\ e-mail: rovelli@spbo.unibo.it
}

This version: July 10, 2000

\begin{abstract}
Bank intermediated short-term capital inflows play a crucial role in the financial structure of many emerging economies. Yet since these funds are subject to the risk of early withdrawal, an excessive reliance on this financing is often associated with a financial or currency crisis. We model a situation where withdrawals are motivated by a change in either the domestic or foreign fundamentals. We show that, for a given change in fundamentals, a sudden reversal in the capital flows, and hence a financial crisis, is more likely the more risk averse are the foreign investors. We also show that a policy to tax early withdrawals may discourage the inflows more likely to cause fundamental runs, as it prevents the relatively more risk averse investors from investing. However, the policy must be fine-tuned to avoid discouraging all capital inflows.
\end{abstract}

Keywords: Short-term capital inflows, Financial fragility, Chilean tax.

JEL codes: G21, G28, O16, 023.

Acknowledgments: This research was undertaken with support from the European Union Phare-ACE Programme 1996, Project No. P96-6114-R. Both authors thank the Studienzentrum Gerzensee for providing logistic support during this research. We thank an anonymous referee, Sudipto Bhattacharya, Elena Carletti, Gianluca Femminis, Luca Lambertini, and several participants at the October 1998 ASSET Conference in Bologna and at the July 2000 ESSET Conference at Gerzensee for useful comments and suggestions. 


\section{Introduction}

In the last six years, emerging market economies have been affected by a long series of financial crises, starting with Mexico in 1994-95, followed by Asia in 1997, Russia in 1998 and Brazil in 1999. Each crisis had its own particular characteristics and determinants. However, they also shared common factors: each demonstrated the "potential for sharp changes in investor sentiment", often triggered by a combination of unsustainable external imbalance, overvalued exchange rate, financial fragility, poorly monitored bank loans, unwise investments, and unsustainable fiscal policy. In this paper we concentrate on one crucial step in the development of such crises: the interplay between financial fragility and deteriorating economic fundamentals. Financial fragility arises when financing capital accumulation via bank-intermediated short-term inflows since they are subject to the risk of early withdrawals. These withdrawals become more likely as the outlook of economic fundamentals gets bleaker and may bring about a sudden reversal of capital flows, precipitating a financial crisis.

We propose a simple unified theoretical framework to evaluate these issues. While simple, our model is useful to analyze the origin of some financial crises, and also to evaluate the effectiveness of a tax on short-term inflows (we call it a Chilean tax as it is equivalent to a requirement on short-term deposits) in reducing the fragility of the financial structure. In particular we show that a Chilean tax works not simply by deterring short-term capital inflows, but more precisely by helping to select less risk averse lenders. In fact we find that, ceteris paribus, a financial crisis is more likely the more risk averse are the investors entering an emerging economy: by selecting out such investors, the tax renders a crisis less probable for any given configuration of the "fundamental" economic variables.

The paper is organized as follows. In section 2 we review the literature and motivate our analysis. In section 3 we set up the basic model to examine the interaction between foreign investors and the financial and industrial sector of an emerging economy. In section 4 we examine under which conditions foreign investment will take place, and in section 5 we characterize under which conditions a crisis will take place. In section 6 we evaluate the role of a Chilean tax in preventing a crisis. Section 7 concludes. 


\section{Short-term capital inflows and financial crises}

The lack of domestic savings is a constraining factor in the growth of most emerging economies. Inflows of foreign capital may help sustain a phase of intensive capital accumulation. Several factors may however deter foreign investments:

- An underdeveloped financial environment. Investing in emerging market economies may be quite difficult for domestic and especially for foreign investors. Financial markets may lack liquidity and transparency while regulations protecting investors' rights are weak or difficult to enforce.

- Demand for liquidity. While acknowledging the need for long-term investments, investors considering investment in an emerging economy may want to keep their options open in the case of either a sudden worsening of conditions in the host economy or a sudden improvement in the financial outlook elsewhere in the world. Thus demand for liquidity is often an integral part of foreign investors' requirements.

- Risk of devaluation. Once an investment has been made, will the foreign investor be able to repatriate her investment into her own currency? Will a sudden devaluation reduce the value of the investment in terms of her consumption basket? Or might the repayment be rescheduled or partially written-off due to balance of payments problems?

The first two issues often direct foreign investors to local banks since they provide ready solutions to both the monitoring and liquidity problems. As for the foreign exchange risk, an investor might to some extent hedge her currency exposure in forward markets, although it is much more difficult to purchase insurance against rescheduling and write-offs.

Based on these considerations, our analysis models foreign investments as channeled through bank deposits into an emerging economy. We do not dispute the importance of other financial instruments, but rather seek a simple framework to highlight what we perceive to be the single most critical aspect of foreign investments into these economies: funds are committed for a shorter period than required for investment to mature and which must be repaid in a foreign currency acquired only after the investment succeeds.

That this is a relevant issue is now widely acknowledged. As Radelet and Sachs (1998) observe: "Much of the economic activity supported by the capital inflows was highly 
productive, and the loss of economic activity resulting from the sudden and enormous reversal in capital flows has been enormous". Several authors have argued that there has been a strong correlation between bank-intermediated short-term inflows and financial crises. For instance, a recent OECD report states that: "ensuring that banks are reasonably sound may not be sufficient to prevent self-fulfilling crises: it is also important to ensure that banks are not exposed to liquidity crises. ... Short-term maturity debt is risky because it increases the potential magnitude of capital outflows. ... It is the ratio of short-term debt to international reserves that matters" (OECD, 1999, pp.83-87). In the same vein, Furman and Stiglitz (1998) observe that, out of a sample of 48 developing nations, 11 had short-term debt ratios to central bank reserves higher than one; of these, only three escaped a currency crisis. Moreover they estimated that the effect of $1 \%$ rise in the ratio of bank debt/total debt may have increased the probability of a crisis by $6 \%$. Also Rodrik and Velasco (1999) observe that the ratio of shortterm bank debt to central bank reserves is a robust predictor of financial crises. They estimate that the probability of a "sharp reversal" in capital flows increases by $3 \%$ to $5 \%$ with a $1 \%$ increase in the ratio.

Parallel to the empirical literature, several authors have examined in theory the relationship between banking arrangements and financial fragility. While a survey of the bank run literature is beyond our scope, we note that several authors have examined the role of the information about fundamentals in precipitating bank runs following the seminal contributions of Bryant (1980) and Diamond and Dybvig (1983). In particular, Jacklin and Bhattacharya (1988) observe that bank runs become a problem only if long-term assets are insufficiently liquid. In their model, moreover, bad news does not necessarily lead to runs if depositors lack alternative stores of value. Accordingly, we also develop below the idea that investors may be induced to run by the presence of attractive outside opportunities. ${ }^{1}$

Papers in the Bryant and Diamond-Dybvig tradition generally examine banking allocations in the context of a closed economy. Recently, several authors have incorporated features of the Diamond-Dybvig model (henceforth: DD) into models of the financial crisis of an emerging economy. In a series of papers, Chang and Velasco $(1998 ; 2000)$ model domestic residents of an emerging economy as risk averse DD investors who may additionally borrow abroad. A

\footnotetext{
${ }^{1}$ Several other papers have examined information-based bank runs. Some authors have proposed the notion of an efficient bank run, i.e. a bank may draft an optimal deposit contract while recognizing the possibility of bank runs (See e.g. Alonso, 1996). However, if one considers the possibility that non-
} 
term structure of interest rates on the foreign liabilities of domestic banks emerges that depends on the relative default risk premia. These authors also find that a flexible exchange rate arrangement with a lender-of-the-last-resort facility is socially optimal. Goldfajn and Valdés (1997) also model a situation where intermediaries may help attract capital inflows although they only consider risk neutral DD investors. In their model, patient investors may start a run if they observe bad news.

Turning to capital controls, several authors favor imposing restrictions or controls on shortterm inflows. The previously quoted OECD report suggests that "in some instances a case can be made for limiting short-term capital inflows through taxes on capital imports, foreign deposit reserve requirements, or similar measures, but global financial integration is driven by forces that cannot easily be reined in and that generally carry many benefits" (OECD, 1999, pp.83-87). In a recent survey, Edwards (1999) observes that capital controls: (i) did not reduce aggregate capital inflows, but instead reduced the ratio of short-term to longer-term debt. (See also Montiel and Reinhart, 1999) (ii) did not affect real exchange rates (iii) did not affect the volatility of short-term interest rates (iv) did significantly affect the level of short-term interest rates (See also De Gregorio, Edwards and Valdés, 1998). These effects (or lack thereof) are entirely consistent with the predictions of our model (see Section 6 below). It is interesting to ask through which mechanism do capital controls operate. In some sense the answer is rather obvious: pecuniary disincentives to invest in short- versus longer-term debt mitigate liquidity problems (provided they do not deter investment altogether). However, the (positive) effects of controls are not limited to this case. For instance, Cordella (1998) argues that a tax on short-term inflows may prevent bank runs and also increase the amount of funds invested. In his model, "rational herding" arises when, after having invested in a long-term project, some investors' early withdrawal engenders anticipated investment liquidation, thus reducing the returns available to the remaining investors. And he finds that imposing a suitably high tax on short-term inflows will effectively discourage herding.

All the above-mentioned papers chose to neglect some crucial aspect of the DD model. In this paper, we model foreign investors as full-fledged DD investors. In particular, our model includes both their aversion to risk and demand for liquidity as essential ingredients. We characterize the banking system of an emerging economy as offering an optimal term structure

informed investors may run prior to the arrival of precise information (used by informed investors), then the notion of efficient runs evaporates (See Chen 1999). 
of deposit rates explicitly tailored to the foreign investors' risk aversion. Higher risk aversion, however, increases the likelihood of a financial crisis for a given dose of bad news. We then find that the imposition of a tax on short-term inflows brings about a steeper term structure of bank offered rates and thus reduces financial fragility, in particular by eliminating the more risk-averse investors, who are the more likely to precipitate a run².

\section{The model}

As the analysis will soon become inherently complicated, we design the model in a suitably simple way. We assume only three agents in the world economy: the productive sector in the emerging economy ("the firm"); the consolidated central bank and commercial banking sector of this economy ("the bank") and foreign investors. The central bank holds foreign reserves as a counterpart to the monetary base (bank reserves), but does not exercise any independent monetary policy, as the structure of domestic rates is a function of technology and investors' preferences. The size and composition of the current and capital account depend on the capital accumulation decisions of domestic firms. There is no fiscal policy and no foreign debt of the government. While these omissions obviously reduce the overall realism of the model, the main point of the analysis stands up more clearly in this simplified setting.

The overall setup and discussion of the model takes places through the following sequence:

a) The firm requests a two period loan from the bank to finance its investment

b) To finance the loan, the bank collects deposit from foreign investors

c) The deposit contract is of the DD type, set for two periods with an option to withdraw after one period

d) Foreign investors also have the outside option to invest in the foreign market

e) New information on fundamentals of the domestic economy arrives in period 1. Under the new circumstances, some foreign investors who would not otherwise have done so decide to seek liquidity, hence to withdraw in period 1

f) A "run" is equivalent to the decision to withdraw in period 1 by depositors who would otherwise have stayed in for 2 periods

g) A run causes a financial crisis, as the bank is subsequently unable to face its obligation towards foreign investors

\footnotetext{
${ }^{2}$ We develop this notion precisely in Section 6 of the paper.
} 
Having examined these issues, we conclude by examining whether, for a given change in fundamentals as in point (e) above, the imposition of a suitably defined "Chilean tax" would reduce the likelihood of a financial crisis.

We examine points (a-c) in this section, point (d) in section 4, points (e-g) in section 5, and we discuss the effects of a "Chilean tax" in section 6.

The firm. The firm begins with no initial resources and so requires initial finance $($ time $=0)$ to purchase imported inputs. The production process is long (2 periods) and partially illiquid in the intermediate (time $=1$ ) period. Each unit of investment at time 0 yields a total return $\mathrm{R}$ $>1$ at time 2 . Thus the periodic rate of return is $\sqrt{\mathrm{R}}-1$. In Section 5.1 we discuss the case when $\mathrm{R}$ is random.

Output produced at time 2 is exported, the proceeds from which repays the initial foreign investment.

Foreign inflows are the only possible source of funds for financing domestic production. While an extreme assumption, it helps us to concentrate on the main ingredient in our story. We would be able to provide no further insight by introducing a parallel domestic source of funds. Moreover, it is a quite realistic assumption: most emerging economies need extensive investment to (re)build their capital stock, an amount which exceeds domestic savings.

Foreign investors. Foreign investment is made in the form of deposits with the domestic bank. Deposits inflow at time 0 and may be maintained for one or two periods with no possibility of pre-commitment. A proportion $0<\varepsilon<1$ of depositors seek to receive at time 1 the pre-agreed rate $r_{1}$ in domestic currency per unit of deposit. The remaining depositors expect to receive at time 2 the contract rate $\left(r_{2}\right)^{2}$ per unit of initial deposit (see below for greater detail on the depositors).

The bank. The bank at time $=0$ receives foreign currency from foreign depositors. This sum is in part converted into local currency and loaned to the firm, which reconverts it into foreign currency to pay for imported inputs. Those initial deposits not loaned to the firm are kept as (foreign currency) reserves in the consolidated banking system. At time $=1$, the bank uses reserves to repay depositors wishing to withdraw early ${ }^{3}$. The role of the central bank in the domestic economy is thus most concisely seen as a currency board. ${ }^{4}$

\footnotetext{
${ }^{3}$ Strictly speaking, eq. (1.2) below should in general be written as a weak inequality. However in the optimum it will always hold as an equality, and for simplicity we use this fact from the beginning.
} 
The consolidated balance sheet of the bank is defined by the following three equations (with inflows on the left, outflows on the right):

$$
\begin{aligned}
& \mathrm{t}_{0}: \quad \mathrm{D}_{0}=\mathrm{F}_{0}+\mathrm{L}_{0} \\
& \mathrm{t}_{1}: \quad \mathrm{r}_{1}^{*} \mathrm{~F}_{0}=\varepsilon \mathrm{r}_{1} \mathrm{D}_{0} \\
& \mathrm{t}_{2}: \quad \mathrm{R} \mathrm{L}_{0}=\left(\mathrm{r}_{2}\right)^{2}(1-\varepsilon) \mathrm{D}_{0}
\end{aligned}
$$

where subscripts refer to the time period and :

$\mathrm{D}=$ foreign deposits,

$\mathrm{F}=$ foreign currency reserves;

$\mathrm{L}=$ loan to domestic firms (also equal to imports at time 0 )

$\mathrm{r}=$ one-period total return to domestic deposits $(1+$ interest rate $)$

$\mathrm{r}^{*}=$ one-period total return to foreign deposits

$\mathrm{R}=$ two-period total return to investments

Eqs. (1.1)-(1.3) are defined in domestic currency. They can be easily written in foreign currency terms by deflating both sides with the current nominal exchange rate $\left(e_{i} ; i=0,1,2\right.$, where $\mathrm{e}$ is the price of one euro in the currency of the emerging economy). Note that, since all and only foreign transactions are intermediated through the bank, the same equations also define the balance of payments of the economy across the three periods. ${ }^{5}$

Determination of interest rates on domestic deposits. In order to evaluate the resource constraint in the final period, substitute (1.1) and (1.2) in (1.3), to obtain:

$$
\mathrm{R}\left(1-\frac{\varepsilon \mathrm{r}_{1}}{\mathrm{r}_{1}^{*}}\right)=\left(\mathrm{r}_{2}\right)^{2}(1-\varepsilon)
$$

that is:

\footnotetext{
Also, we could alternatively assume that the bank may finance these intermediate-deposit withdrawals borrowing (on the world financial market, at the going riskless rate, $\mathrm{r}_{2}{ }^{*}$ ) based on the proceeds from final-period exports. This strategy would not improve on the one described in the text.

${ }^{4}$ While we could assume that the central bank creates additional high-powered money to finance domestic credit creation, this complication would not add insight.

${ }^{5}$ From the balance of payments perspective, $\mathrm{D}_{0}$ is the capital inflow, $\mathrm{F}_{0}$ is the capital outflow and $\mathrm{L}_{0}$ are imports, all at time 0 . At time $1, r_{1} * F_{0}$ is the capital and interest inflow and $\varepsilon r_{1} D_{0}$ is the capital and interest outflow. Finally, at time $2, \mathrm{R} \mathrm{L}_{0}$ are exports and $(1-\varepsilon)\left(\mathrm{r}_{2}\right)^{2} \mathrm{D}_{0}$ is the capital and interest outflow.
} 


$$
\left(\mathrm{r}_{2}\right)^{2}=\frac{\mathrm{R}}{1-\varepsilon}\left(1-\frac{\varepsilon \mathrm{r}_{1}}{\mathrm{r}_{1}^{*}}\right)
$$

Also, we assume now but shall justify later (see section 4) the following relationship between domestic and foreign returns:

$$
\mathrm{R} \geq \mathrm{r}_{1} * \mathrm{r}_{2} * \text { with both } \mathrm{r}_{1} *, \mathrm{r}_{2} * \geq 1
$$

In order to find explicit solutions for $r_{1}$ and $r_{2}$ (for parametric $r_{1}^{*}, R$, and $\varepsilon$ ) we need to model foreign investors' characteristics and preferences. We assume, following Diamond and Dybvig (1983), that foreign investors can be either "patient" (i.e., they want to withdraw and consume at time 1) or "impatient" (they prefer to withdraw and consume at time 2). Their type becomes privately known before the beginning of time 1, that is, after making time 0 decisions, but before time 1 (withdrawal/reinvestment) decisions. It is, however, private information unobservable to others. There is no aggregate uncertainty about the proportion of impatient vs. patient investors ( $\varepsilon$ vs. 1-E). Apart from their type (unknown at time 0), investors are homogeneous: in particular they have the same endowment and the same degree of aversion to risk. Later in section 6, we shall assume that investors differ also in their aversion to risk.

If investors were risk neutral, they would maximize the expected return to their portfolios by choosing $r_{1}=\varepsilon r_{1}=0$. Hence impatient types would not obtain a return. In this case, there would be no need to allow for "liquidity" contracts since intermediate withdrawals and financial fragility would never become an issue.

Let us then turn to the more interesting case of risk averse investors. Assume the consolidated banking system includes a central bank and a competitive banking system. Banks then act as if they were maximizing investors' expected utility ${ }^{6}$. Thus:

$$
\operatorname{Max}\left[\varepsilon \mathrm{U}\left(\frac{\mathrm{r}_{1}}{\mathrm{e}_{1}}\right)+(1-\varepsilon) \mathrm{U}\left[\frac{\left(\mathrm{r}_{2}\right)^{2}}{\mathrm{e}_{2}}\right]\right]
$$

Substitute eq.(2) in (3). We have:

\footnotetext{
${ }^{6}$ This can be justified, given that competitors face the same budget constraints, either because domestic bank competition forces them to offer contractual conditions that cannot be improved (and to zero profits) or because the investor chooses among investments of many emerging economies, thus forcing locally monopolistic bank sectors to behave competitively vis-à-vis banks of other emerging economies.
} 


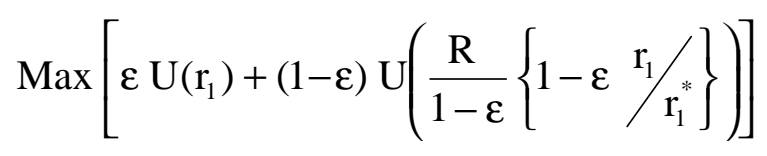

and the associated FOC:

$$
\mathrm{U}^{\prime}\left(\mathrm{r}_{1}\right)-\mathrm{U}^{\prime}\left[\left(\mathrm{r}_{2}\right)^{2}\right] \cdot \frac{\mathrm{R}}{\mathrm{r}_{1}^{*}}=0
$$

To obtain an explicit solution, assume U(.) to have CRRA. Thus:

$$
\mathrm{U}(\mathrm{r})=\frac{\mathrm{r}^{\gamma}}{\gamma} ; \gamma<1 \quad \leftrightarrow \quad \mathrm{RRA}=1-\gamma
$$

In this case, (5) becomes:

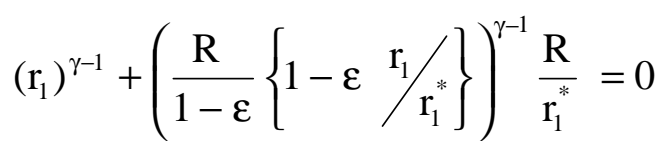

Solving for the first period interest rate we obtain:

$$
\mathrm{r}_{1}=\frac{\mathrm{r}_{1}^{*}}{\varepsilon+(1-\varepsilon)\left(\mathrm{R} / \mathrm{r}_{1}^{*}\right)^{\gamma /(1-\gamma)}}
$$

which we can then use in (2) to solve for the second-period interest rate.

Properties of deposit contract. The competitive (utility maximizing) contract is obtained by sequentially solving eqs. (8) and (2). ${ }^{7}$ We notice that, for RRA>1 (greater than log utility) ${ }^{8}$

$$
\mathrm{r}_{1} *<\mathrm{r}_{1}<\mathrm{r}_{2}<\mathrm{R}
$$

We also notice by inspection of eq. (8) that the first period interest rate $\left(r_{1}\right)$ is:

- decreasing in $\varepsilon$

- increasing (but less than one-for-one) in both $\mathrm{R}$ and $\mathrm{r}_{1}$ *

- increasing as risk aversion increases ( $\gamma$ decreases).

On the other hand, from eq. (2), upon substitution of eq. (8), we notice that $r_{2}$ decreases with greater risk aversion. Hence there exists a degree of risk aversion $\left(1-\gamma^{\circ}\right)$ corresponding to the interest rate where the one is equal to the other (See von Thadden, 1997). For $\gamma<\gamma^{\circ}$ the

\footnotetext{
${ }^{7}$ Note that a benchmark case in assessing the degree of risk aversion is the log utility function. It has a relative risk aversion equal to 1 , which corresponds to $\gamma=0$ in equation (6).

${ }^{8}$ If $0<\gamma<1$, than optimal deposit rates would not be bounded by $\left(r_{1} *, R\right)$, i.e.: $r_{1}<r_{1} *<R<r_{2}$.
} 
term structure of deposit rates slopes downwards (see below for the implications that such a term structure would have in our setup).

The analytical expression for $\gamma^{\circ}$ is rather complicated and by itself uninteresting (see Appendix, A.1). Numerical values of $\gamma^{\circ}$ are quite reasonable, however. For example, using equation (A.1), we find that:

- with $\varepsilon=.7, \mathrm{R}=1.5$, and $\mathrm{r}_{1} *=1.05$, then $\gamma^{\circ}=-2.090$ and $\mathrm{r}_{1}=\mathrm{r}_{2}=1.122$

- with $\varepsilon=.3, \mathrm{R}=1.3$, and $\mathrm{r}_{1} *=1.00$, then $\gamma^{\circ}=-1.463$ and $\mathrm{r}_{1}=\mathrm{r}_{2}=1.112$

- with $\varepsilon=.2, \mathrm{R}=1.2$, and $\mathrm{r}_{1}^{*}=1.05$, then $\gamma^{\circ}=-0.546$ and $\mathrm{r}_{1}=\mathrm{r}_{2}=1.090$.

We may ask at this point the extent to which a withdrawable deposit contract is the appropriate financing instrument. For instance, a syndicated loan is an alternative contract that could help to solve the monitoring problems associated with lending to an emerging country. However, Calomiris and Kahn (1991) argue that the usefulness of demandable deposits follows from their facilitation of information-sharing between investors who are monitors and those who are not. In this context the characteristic valued most by investors is the option to force the bank to liquidate. Calomiris and Kahn find that, for a wide range of parameter values, the potential liquidation cost may be more than offset by the social gain arising from the greater investment these contracts stimulate. The fact that, in the real world, bankintermediated short-term deposits provide a significant proportion of total foreign debt of emerging economies ${ }^{9}$ suggests that the opportunity to use a withdrawable instrument is indeed valued by investors.

\section{To invest or not to invest?}

Foreign investors choose among the following opportunities to maximize their expected utility as of time 0 :

1. stay out of country: obtain $r_{1} *$ (and, if of patient type, then also $r_{2} *$ later )

2. invest (deposit) in the emerging country for one period and:

2.1. either withdraw and disappear (if impatient), after earning $r_{1} / e_{1}$ (in foreign currency)

2.2. or (if patient) reinvest for the second period in one of the following three alternatives :

2.2.1. earn $r_{1} / e_{1}$ and reinvest in same country, earning (for both periods) $r_{1} r_{1} / e_{2}$ 
2.2.2. earn $r_{1} / e_{1}$ and reinvest in foreign market, earning (for both periods) $\left(r_{1} / e_{1}\right) r_{1} *$

2.2.3. stay invested in deposit contract, earning for the whole period $\left(\mathrm{r}_{2}\right)^{2} / \mathrm{e}_{2}$.

Since at time $=0$ all investors have identical risk aversion and endowments, they make the same decision. (They differ by type, but do not discover this until time =1). Assume that a deposit contract of the type discussed in the previous paragraph is offered, with interest rates given by eqs. (8) and (2) respectively. We call such contract a DD contract. In particular, this allows for the possibility of either an intermediate withdrawal (time $=1$ ) with total return $\mathrm{r}_{1} \underline{\text { or }}$ a final withdrawal with total return $\left(\mathrm{r}_{2}\right)^{2}$, at the demand of the depositor.

We first identify the set of parameters for which such a contract will be accepted. Later, we will appropriately modify the model in equation (4). And, assuming the contract has been accepted on the basis of a given expected distribution of future variables $\left(\mathrm{R}, \mathrm{r}_{2}{ }^{*}\right)$, we will examine whether a patient depositor might be induced to reconsider her choice and withdraw after observing the realized values of these variables in the intermediate period.

In this section we examine the first issue, while the second issue is discussed in section 5 . The question we pose here is: under what circumstances will an investor decide whether to invest in the emerging economy, and (conditional on having invested and on being a patient type) will she also expect to continue the investment throughout the second period?

The following constraints, to be evaluated at time 0 , ensure a positive answer to this question:

- C.1: do not stay out: $\quad \mathrm{EU}\left(\mathrm{r}_{1}, \mathrm{r}_{2}\right)>\mathrm{EU}\left(\mathrm{r}_{1} *, \mathrm{r}_{2} *\right)$

- C.2: do not go short: $\quad E U\left(r_{1}, r_{2}\right)>E U\left(r_{1}, r_{1}\right) \quad \Rightarrow \quad r_{2} \geq r_{1}$

- C.3: expect to stay in: $\quad E U\left(r_{1}, r_{2}\right)>E U\left(r_{1}, r_{2}^{*}\right) \quad \Rightarrow \quad\left(r_{2}\right)^{2}>r_{1} r_{2} *$

If these constraints are satisfied, the foreign deposit (and the corresponding capital inflow) will take place and domestic production will be financed. This process will be interrupted only if a run (unexpected at time 0) will occur at time 1 . Before we discuss this case, however, we must find under which conditions the constraints C.1-C.3 will be satisfied. This is done below.

Assumptions:

\footnotetext{
${ }^{9}$ For instance, Rodrik and Velasco (1999) show that between 1991 and 1997 short-term bankintermediated debt has consistently been above $20 \%$ of total foreign debt for the Asia-Pacific countries (while it has always been below 12\% for European countries).
} 
- A.0 $\mathrm{r}_{1}^{*}, \mathrm{r}_{2} * \geq 1$

- A.1 $1>\gamma \geq 0 \quad$ and $\quad \mathrm{R}>\mathrm{r}_{1} * \mathrm{r}_{2} *>1$

- A.2 $0>\gamma \geq \gamma^{\circ} \quad \underline{\text { and }} \quad \mathrm{R}>\mathrm{r}_{1} *\left(\mathrm{r}_{2}\right)^{1-\gamma}>1$

\section{Proposition 1.}

If assumptions A.O and either A.1 or A.2 are satisfied, then constraints C1-C.3 are also satisfied.

\section{Proof:}

(i) A.0 is required to ensure that investing in the foreign market is preferable than holding currency throughout.

(ii) To see that C.1 is satisfied, assume $r_{1}=r_{1} *$, and then note that in this case, by eq. (2), $\left(r_{2}\right)^{2}=R$, or equivalently $r_{2}=\sqrt{R}$. Then also note that, by definition of expected utility: $\quad \quad E U\left(r_{1}^{*}, \sqrt{R}\right)=\varepsilon U\left(r_{1}^{*}\right)+(1-\varepsilon) U(R)$, and $\quad \mathrm{EU}\left(\mathrm{r}_{1}^{*}, \mathrm{r}_{2}^{*}\right)=\varepsilon \mathrm{U}\left(\mathrm{r}_{1}^{*}\right)+(1-\varepsilon) \mathrm{U}\left(\mathrm{r}_{1}^{*} \mathrm{r}_{2}^{*}\right)$.

Also, by A.1: $\quad \mathrm{U}(\mathrm{R})>\mathrm{U}\left(\mathrm{r}_{1} * \mathrm{r}_{2} *\right)$.

This proves that $\quad \mathrm{EU}\left(\mathrm{r}_{1} *, \sqrt{\mathrm{R}}\right)>\mathrm{EU}\left(\mathrm{r}_{1} *, \mathrm{r}_{2} *\right)$.

Finally, note that: $\quad \mathrm{EU}\left(\mathrm{r}_{1}, \mathrm{r}_{2}\right) \geq \mathrm{EU}\left(\mathrm{r}_{1} *, \sqrt{\mathrm{R}}\right)$

since both sides are obtained under the same resource constraint (eq.2), and the 1.h.s. is by hypothesis the expected-utility-maximizing contract. By joining the last two inequalities, $\mathrm{C} 1$ follows.

(iii) Observe that C.2 is always satisfied for $1>\gamma>0$. Also, as we show in eq. (A.1) in the Appendix, it is always possible to find a value $\gamma^{\circ}<0$ such that, for all $\gamma \geq \gamma^{\circ}$, C.2 is satisfied, and for all $\gamma<\gamma^{\circ}$ C.2 is not satisfied. Hence $\gamma \geq \gamma^{\circ}$ is required to satisfy C.2.

(iv) Rearrange C.3 and observe that it is satisfied as long as $\mathrm{R}>\mathrm{r}_{1} *\left(\mathrm{r}_{2} *\right)^{1-\gamma}$. This is more stringent than the requirement for C.1 only if $\gamma<0$. Hence the joint satisfaction of all three constraint requires assumption A. 0 and either A.1 or A.2 to be satisfied. 


\section{To run or not to run?}

In order to discuss whether the good equilibrium of the model, as characterized so far, will in fact be realized, or whether instead a run on the currency will occur, it is first useful to summarize how events and decisions occur along the time line. See Table 1.

In particular, we seek the parameter values for a deposit made at time 0 by an investor who turned out (at time 1--) to be "patient". We are interested whether the deposit will be maintained in the second period or is withdrawn due to new information arriving at time 1-. Moreover, for the cases in which a run would occur, we ask whether alternative policies could have been adopted to avoid it (although we postpone this discussion until section 6). Here instead we concentrate on analyzing how the arrival of information at time 1- might change investors' attitudes and induce a run out of the country, one that was not expected at time 0 .

\section{Table 1. The time line}

\begin{tabular}{|c|c|}
\hline Time 0 & $\begin{array}{l}\text { Firm makes initial investment decision and requests loan from the bank. } \\
\text { If }\{\text { C. } 1, \text { C. } 2, \text { C. } 3\} \text { satisfied, foreign investors make deposit at the bank. } \\
\text { Loan is given to firm and production starts. }\end{array}$ \\
\hline Time 1- - & Type of investors becomes privately known. \\
\hline Time 1- & $\begin{array}{l}\text { Patient depositors observe realized values of uncertain exogenous variables } \\
\left(\mathrm{R}, \mathrm{r}_{2}^{*}\right) \text {. }\end{array}$ \\
\hline Time 1 & $\begin{array}{l}\text { Patient depositors either confirm decision to invest until period } 2 \text { or decide to } \\
\text { withdraw. } \\
\text { If also (some) patient-types withdraw, run occurs, liquidate bank assets, and a } \\
\text { financial crisis follows. }{ }^{10} \\
\text { Impatient investors earn the contracted deposit rate, } \mathrm{r}_{1} \text {, or alternatively, } \\
\text { everyone divides the bank's liquidation value (on a first-come, first-served } \\
\text { basis). }\end{array}$ \\
\hline Time 2 & $\begin{array}{l}\text { If run has not occurred: Production realized and exported. } \\
\text { Exports are used to pay depositors (at the same exchange rate that had been } \\
\text { expected at time } 0 \text {, provided a run has not occurred). }\end{array}$ \\
\hline
\end{tabular}

\footnotetext{
${ }^{10}$ Here we use the generic definition of a financial crisis to encompass several different outcomes, which may or may not occur depending on other institutional arrangements in the emerging economy. For instance, under a currency board arrangement, the commercial bank will fail, and the loss of reserves at the central bank will induce a monetary contraction. With a flexible exchange rate arrangement, the domestic currency would instead devalue. Moreover, if the bank had financed the firm with a 2-period loan, production would continue. If instead the firm had been financed with a callable loan or with a sequence of one-period loans, then also the productive sector would face bankruptcy. These are obviously extremely relevant issues, however we do not feel that it is necessary to discuss them in the present paper.
} 
At time 1- may observe new information corresponding to two different set of events. The new information may refer to either:

- profitability of the real investment in the emerging economy : $\mathrm{R}$

- state of the world in period 2: $\mathrm{r}_{2}{ }^{*}$

If either of these variables is uncertain, we must modify the former maximization problem, which yields a generally different solution for $r_{1}$ (specifically, equation (8) is no longer valid). Equation (2), though, continues to be valid in expectation. We must also evaluate Constraints C1-C.3 to to take into account that expected utility is now a function of both the investors' types and of the variability of either future profitability or future state of the world (or both).

For tractability, we shall assume a binomial distribution (for either $\mathrm{R}$ or $\mathrm{r}_{2}{ }^{*}$ ), taking one source of uncertainty at a time, in Sections 5.1 and 5.2 respectively. In section 5.3 we state the main proposition on fundamental runs.

\subsection{Uncertainty in final outcome}

To model the existence of uncertainty in final return to the domestic technology, we assume a simple binomial distribution. Define $\mathrm{R}^{\mathrm{u}}>\mathrm{R}^{\mathrm{d}}$ (respectively "good" and "bad") as the possible values the final return may assume, with probabilities $q$ and (1-q) respectively. Next, to reformulate the maximization problem of equation (4), we must encompass that at time 0 , the investor computes expected utility out of four possible occurrences:

- she is impatient and patient investors do not run [payoff to impatient: $r_{1}$ ]

- she is patient (prob. 1- $\varepsilon$ ) and the good outcome occurs (prob. q) [payoff: $\left.\left(\mathrm{r}_{2}{ }^{\mathrm{u}}\right)^{2}\right]^{11}$

- she is patient and the bad outcome occurs, but no run follows [payoff: $\left(\mathrm{r}_{2}{ }^{\mathrm{d}}\right)^{2}$ ]

- the bad outcome occurs and everyone decides to run ${ }^{12}$

To compute the expected utility, we need the probability of each outcome, which we know except for the probability of the run. However, assume the joint event of being a patient type

\footnotetext{
${ }^{11} \mathrm{r}_{2}{ }^{\mathrm{u}}$ and, below, $\mathrm{r}_{2}{ }^{\mathrm{d}}$ are one-period total returns earned by remaining invested in the contract for two periods, based on returns to the underlying technology of $\mathrm{R}^{\mathrm{u}}$ or $\mathrm{R}^{\mathrm{d}}$. These returns are computed from equation (2).

${ }^{12}$ Resources available at time 1 , before withdrawals and repayments, are: $\mathrm{A}_{1} \equiv \mathrm{r}_{1} * \mathrm{~F}_{0}+\mathrm{q} \mathrm{L}_{0}$, where $\mathrm{q}$ is the liquidation value of the investment in the intermediate period, and $0<\mathrm{q} \leq 1$. Hence the intermediate return per unit of deposit in case of anticipated liquidation of the bank is $A_{1} / D_{0}$. This assumes that impatient depositors and "runners" are treated alike when the bank is liquidated.
} 
who has observed the bad outcome. In this case, the agent decides she will not run if the following constraint (evaluated at time 0 ) is satisfied ${ }^{13}$ :

$$
\text { - C.4.1 }\left(\mathrm{r}_{2}{ }^{\mathrm{d}}\right)^{2} \geq \mathrm{r}_{1} \mathrm{r}_{2}{ }^{*} \text {. }
$$

In this section, we concentrate on the case when a run does not occur, and in sections 5.3 and 6 we examine in more detail what variables (or news) and policies would make the constraint C.4.1 more or less likely to be satisfied.

It might be meaningful to investigate an efficient run, i.e. when an investor rationally anticipates a run if a bad outcome occurs, but nevertheless finds it attractive (in expected utility terms, computed at time 0) to invest in the emerging country. However, while an efficient run may be interesting in the case of a single bank, it is much less plausible extended to an aggregate banking system. Hence, we rule it out, assuming that an aggregate run (one affecting the entire banking system) is too costly to accept, so banks will not accept deposits if such an event were likely (that is, if C.4.1 is not satisfied). Accordingly, the assumption of constraint C.4.1 is entirely appropriate in our context, and so we compute the investor's expected utility under the possible occurrence of three events only:

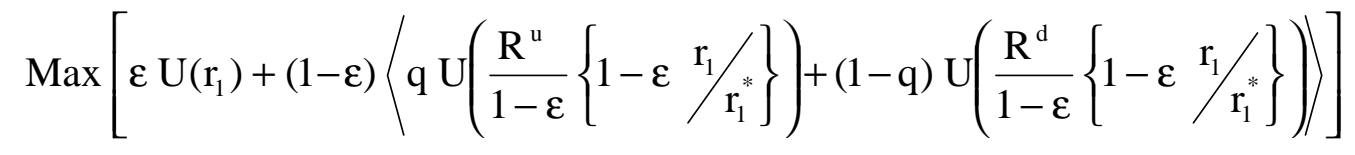

Note that as a result of the uncertainty, contract rate $\mathrm{r}_{2}$ will de facto be indexed to the realized value of $\mathrm{R}$. This might seem counterfactual, given the usual specification of deposit contracts. However it need not be if one interprets the value of $r_{2}\left(R^{d}\right)$ as either the result of a partial write-off of debt or, in a richer model, as isomorphic to a currency devaluation occurring if too little output had been produced to repay the foreign debt based on a constant (from time 0 to time 2) exchange rate.

\subsection{Uncertainty in the world interest rate}

Several authors have indicated a role for external factors in precipitating banking crises in emerging markets. For instance, Eichengreen and Rose (1998) find that increasing interest rates in industrialized countries are strongly associated with the onset of banking crises in

\footnotetext{
${ }^{13}$ The constraints states a necessary and sufficient condition for the non-occurrence of a run. Note that the cutoff point for an investor not to run is indeed $r_{1} r_{2}{ }^{*}$ since she evaluates the return without
} 
developing countries. In this section, we extend our model to take account of volatility in the second period foreign interest rate, $r_{2} *$. To do so, we retain equation (4) but we modify those constraints that depend on the value of $r_{2}{ }^{*}$. Thus, for constraint C.1, we specify the expected utility of staying out as:

$$
\mathrm{EU}\left(\mathrm{r}_{1}^{*}, \mathrm{r}_{2}^{*}\right)=\varepsilon \mathrm{U}\left(\mathrm{r}_{1}^{*}\right)+(1-\varepsilon)\left\langle\mathrm{p} \mathrm{U}\left(\mathrm{r}_{2}^{* \mathrm{u}}\right)+(1-\mathrm{p}) \mathrm{U}\left(\mathrm{r}_{2}^{* \mathrm{~d}}\right)\right\rangle
$$

where we have assumed, similarly to the previous section, a binomial distribution for the foreign interest rate in the second period..$^{14}$

Assuming again that constraints C.1-C.3 (the former modified to include equation (9)) are satisfied, will the patient investor confirm his decision to remain invested in the emerging country when $\mathrm{r}_{2} *$ is observed? This question is critical only in case of a "high" realized value, i.e. $\mathrm{r}_{2}{ }^{\mathrm{u}}$. Alternatively, if patient depositors "stay in", they earn - with certainty - $\left(\mathrm{r}_{2}\right)^{2}$. Therefore, they choose not to withdraw iff the following constraint is satisfied:

- C.4.2: continue to stay in: $\quad\left(r_{2}\right)^{2}>r_{1} r_{2} *^{u}$

In this case, the investor's maximization problem is again described by equation (4).

\subsection{Likelihood of a run upon observing new information}

We first define a fundamental run as follows:

\section{Definition: Fundamental Run}

If a bank has accepted deposits, a fundamental run will occur when $\{C .1, C .2, C .3\}$ are satisfied and either C.4.1 or C.4.2 are not.

Let us re-examine constraint C.4.1: $\left(\mathrm{r}_{2}{ }^{\mathrm{d}}\right)^{2} \geq \mathrm{r}_{1} \mathrm{r}_{2}{ }^{*}$. For given second period foreign interest rates, the constraint will be less likely to bind, the higher the return to the depositors if a bad outcome to the technology, $\mathrm{r}_{2}{ }^{\mathrm{d}}$, or the lower the first period bank contract rate. This observation provides the intuition for the following:

internalizing the consequences of a run on the value of the bank in liquidation.

${ }^{14}$ The bank could alternatively offer a second period interest rate indexed to the world rate, i.e. $r_{2}=$ $\mathrm{r}_{2}\left(\mathrm{r}_{2}{ }^{*}, \mathrm{R}\right)$. However, the resource constraint, eq. (2), must still hold. Hence the bank must also index first period contract rates to the same rate, i.e. $r_{1}=r_{1}\left(r_{2}{ }^{*}, R\right)$. This implies $r_{1}$ could not be paid until $r_{2}{ }^{*}$ is observed, which we plausibly assume cannot be done in our context. This rules out indexing $r_{2}$. 


\section{Proposition 2.1}

A fundamental run in case of uncertain profitability of the real investment would be more likely:

- $\quad$ the more variable is $R$

- the more risk averse are the investors.

Proof: See Appendix, A.2.

We apply similar reasoning to constraint C.4.2: $\left(\mathrm{r}_{2}\right)^{2}>\mathrm{r}_{1} \mathrm{r}_{2}{ }^{\mathrm{u}}$. The constraint clearly becomes less binding, the "steeper" is the domestic term structure (for given foreign rates) and the lower are the foreign rates. This provides the intuition for the following:

\section{Proposition 2.2}

A fundamental run in case of uncertain value of world interest rates would be more likely:

- the more variable are world interest rates

- the more risk averse are the investors.

Proof: See Appendix, A.3.

Table 2 provides numerical examples concerning Proposition 2.2. We examine three cases characterized by uncertainty in $\mathrm{r}_{2}{ }^{*}$, which may take values 1.2 or 1.0 with equal probability (equivalent to interest rates of $20 \%$ and 0 respectively). The three cases assume equal degrees of risk aversion and parameters differing only in $\varepsilon$, the proportion of "impatient" investors, respectively $0.1,0.5,0.9$. We observe in the first two cases that capital will not flow into the economy: constraint C.2 binds in both cases. On the other hand, $(\varepsilon=0.9)$ the inflow occurs in the third case, but will be reversed (a run occurs) in the "bad" state of the world (i.e. world interest rates up to $20 \%$ ). 
Table 2. Uncertain world interest rates, with or without a run

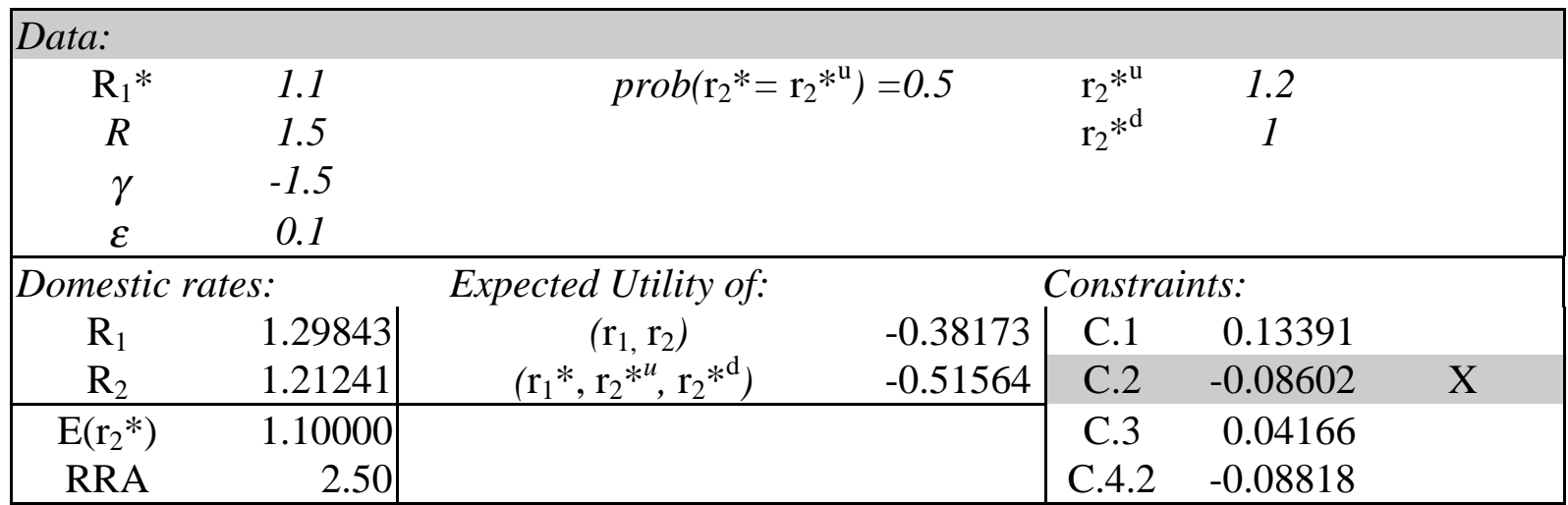

\begin{tabular}{|c|c|c|c|c|c|c|}
\hline \multicolumn{7}{|l|}{ Data: } \\
\hline $\mathrm{R}_{1} *$ & 1.1 & \multirow{4}{*}{\multicolumn{2}{|c|}{$\operatorname{prob}\left(\mathrm{r}_{2} *=\mathrm{r}_{2} *^{\mathrm{u}}\right)=0.5$}} & $\mathrm{r}_{2} *^{\mathrm{u}}$ & 1.2 & \\
\hline$R$ & 1.5 & & & $\mathrm{r}_{2} *^{\mathrm{d}}$ & 1 & \\
\hline$\gamma$ & -1.5 & & & & & \\
\hline$\varepsilon$ & 0.5 & & & & & \\
\hline \multicolumn{2}{|c|}{ Domestic rates: } & \multirow{3}{*}{$\begin{array}{l}\text { Expected Utility of: } \\
\qquad\left(\mathrm{r}_{1}, \mathrm{r}_{2}\right) \\
\left(\mathrm{r}_{1} *, \mathrm{r}_{2} *^{u}, \mathrm{r}_{2}{ }^{\mathrm{d}}\right)\end{array}$} & & \multicolumn{2}{|c|}{ Constraints: } & \\
\hline $\mathrm{R}_{1}$ & 1.20206 & & -0.46290 & C.1 & 0.08039 & \\
\hline $\mathrm{R}_{2}$ & 1.16655 & & -0.54329 & C. 2 & -0.03551 & $\mathrm{X}$ \\
\hline $\mathrm{E}\left(\mathrm{r}_{2} *\right)$ & 1.10000 & & & C. 3 & 0.03857 & \\
\hline RRA & 2.50 & & & C. 4.2 & -0.08164 & \\
\hline
\end{tabular}

\begin{tabular}{|c|c|c|c|c|c|c|}
\hline \multicolumn{7}{|l|}{ Data: } \\
\hline $\mathrm{R}_{1} *$ & 1.1 & \multicolumn{2}{|c|}{$\operatorname{prob}\left(\mathrm{r}_{2} *=\mathrm{r}_{2} *^{\mathrm{u}}\right)=0.5$} & $\mathrm{r}_{2} *^{\mathrm{u}}$ & \multirow{4}{*}{\multicolumn{2}{|c|}{$\begin{array}{c}1.2 \\
1\end{array}$}} \\
\hline$R$ & 1.5 & & & \multirow{3}{*}{$\mathrm{r}_{2} *^{\mathrm{d}}$} & & \\
\hline$\gamma$ & -1.5 & & & & & \\
\hline$\varepsilon$ & 0.9 & & & & & \\
\hline \multicolumn{2}{|c|}{ Domestic rates: } & Expected Utility of: & & \multicolumn{2}{|c|}{ Constraints: } & \\
\hline $\mathrm{R}_{1}$ & 1.11900 & $\left(\mathrm{r}_{1}, \mathrm{r}_{2}\right)$ & -0.55364 & C. 1 & 0.01731 & \\
\hline $\mathrm{R}_{2}$ & 1.12552 & $\left(\mathrm{r}_{1} *, \mathrm{r}_{2} *^{u}, \mathrm{r}_{2} *^{\mathrm{d}}\right)$ & -0.57094 & \multirow{2}{*}{$\begin{array}{l}\text { C. } 2 \\
\text { C. } 3\end{array}$} & 0.00652 & \\
\hline \multirow{2}{*}{$\begin{array}{l}\mathrm{E}\left(\mathrm{r}_{2}{ }^{*}\right) \\
\mathrm{RRA}\end{array}$} & \multirow{2}{*}{$\begin{array}{r}1.10000 \\
2.50\end{array}$} & & & & 0.03590 & \\
\hline & & & & C. 4.2 & -0.07600 & RUN \\
\hline
\end{tabular}

Note: In the last column, an $\mathrm{X}$ denotes that a time- 0 constraint is binding, hence foreign investors would not want to invest in the country; a RUN instead denotes that the bank would not want to accept foreign investments, because if it did there would be some non-zero probability of a run. 


\section{Policies to prevent currency runs}

In the previous sections we have identified that for certain parameter values, a "fundamental" run may occur (if the bank accepts the funds that foreign depositors would supply). As the possibility of a run can be anticipated at time 0, we argued in section 5.1 that the bank would more likely consider the significant bankruptcy costs associated with a run and reject deposits altogether if either constraint C.4.1 or C.4.2 is not satisfied. Nevertheless, it is clearly desirable to institute policies that widen the range of parameters values for which such constraints do not bind, and thus allow greater delivery of "safe" capital inflows. Is it possible to at least reduce the likelihood of runs, while avoiding radical therapy (à la Mahatir) - i.e. without discouraging capital inflows tout court? In general, we might consider several policies:

- tax short-term inflows, or impose a non-remunerated reserve requirement ${ }^{15}$

- increase reserves ex ante, (which implies reducing loans to firms)

- finance withdrawals by borrowing in the intermediate period; repay in the final period by taxing realized output (assuming the taxing authority has the authority to access foreign exchange obtained from exports).

Note that in each of these three cases the resource constraint (eq.2) changes accordingly. ${ }^{16}$ The more interesting and widely debated policy suggestion is certainly the first and so we propose to examine it analytically within the framework of our model.

\subsection{A tax on short-term inflows}

We now investigate the imposition of a tax on short-term inflows (sometimes denoted a "Chilean tax") that reduces the return paid to the foreign investors withdrawing in the intermediate period (either because they discover they are "impatient" or because they have observed unfavorable information at time 1-). In our model, this tax may be structured in one of two ways:

\footnotetext{
${ }^{15}$ While the two policy instruments are operationally different, there is a one to one correspondence between them, expressed by the formula: $t(m)=r_{1} *[\lambda /(1-\lambda)](M / m)$, where $t$ is the tax rate, $m$ is the actual length of the investment, $M$ is the period for which the reserve deposit has to be maintained and $\lambda$ is the coefficient of required reserve. See Edwards (1999) for references to the original sources of this formula and some examples.
} 
- The tax reduces the amount paid to first period withdrawals while the bank holds no reserves against the tax, hence the tax revenues are invested for two periods in the firm.

- Hold reserves equal to the amount of gross first period interest. Pay net interest to depositors while the tax goes to the government (consolidated with the central bank), which then earns the prevailing foreign rate $r_{2} *$ on its revenues.

In the first case the tax is arbitraged away since contract terms are endogenous. Hence we consider only the second case. Proposition 3 establishes the effects of the tax on the term structure of deposit interest rates and verifies that the tax does not discourage investments (by making the constraints C1-C.3 binding).

\section{Proposition 3.}

A tax on short-term inflows has the following effects:

- lowers $r_{1}$ (net of tax)

- for any other given parameter values, makes the constraint C.1 more binding

- $\quad$ for $\gamma<0$, lowers, and for $0<\gamma<1$, increases second period interest rates

- may discourage foreign deposits that would have occurred had the tax been zero.

Proof: See Appendix, A.4.

The results in Proposition 3 are to some extent intuitive. However, they are really a foundation for a subtler thought-provoking statement that requires a more realistic set of assumptions in our model. We relax the assumption of homogenous foreign investors (apart from their liquidity type) and assume instead they have two different degrees of aversion to risk; characterized by high $(\mathrm{H})$ or low $(\mathrm{L})$ risk aversion.

Imagine the following experiment, a situation in which both $\mathrm{H}$ and $\mathrm{L}$ investors wish to invest in an emerging economy. Introduce a tax on short-term inflows and gradually increase the tax rate. The tax will affect the constraints of both groups of investors. Whose constraints will start biting first, those of the $\mathrm{H}$ or of the $\mathrm{L}$ investors? And is the answer to this question related to the results stated in Propositions 2.1 and 2.2? The answer, as shown in the statement of Proposition 4, turns out to be rather favorable.

Proposition 4. A tax on short-term inflows helps to select the less risk averse investors.

\footnotetext{
${ }^{16}$ In particular in the latter case the constraint would become more slack as borrowing to finance withdrawals allows reducing, or in the limit to eliminating, initial reserves. This in turns yields an increased amount of output in period 2.
} 


\section{Proof. See Appendix, A.5.}

Discussion. Figure 1 shows the highest tax for which $\mathrm{H}$ accepts the contract (it remains acceptable to $\mathrm{L}$ ) for given $\mathrm{r}_{1} *=\mathrm{r}_{2} *=1, \mathrm{R}=1.5$ (the graph does not change appreciably with other values of $r_{1} *, r_{2}^{*}$, or $R$ ). With higher $\varepsilon$, a lower tax rate separates the $H$ and $L$ investors. This is because a higher $\varepsilon$ places greater weight on first period, taxed, consumption in the utility of investors, so a tax increase decreases utility more strongly than when second period consumption is more heavily weighted (i.e. lower $\varepsilon$ ).

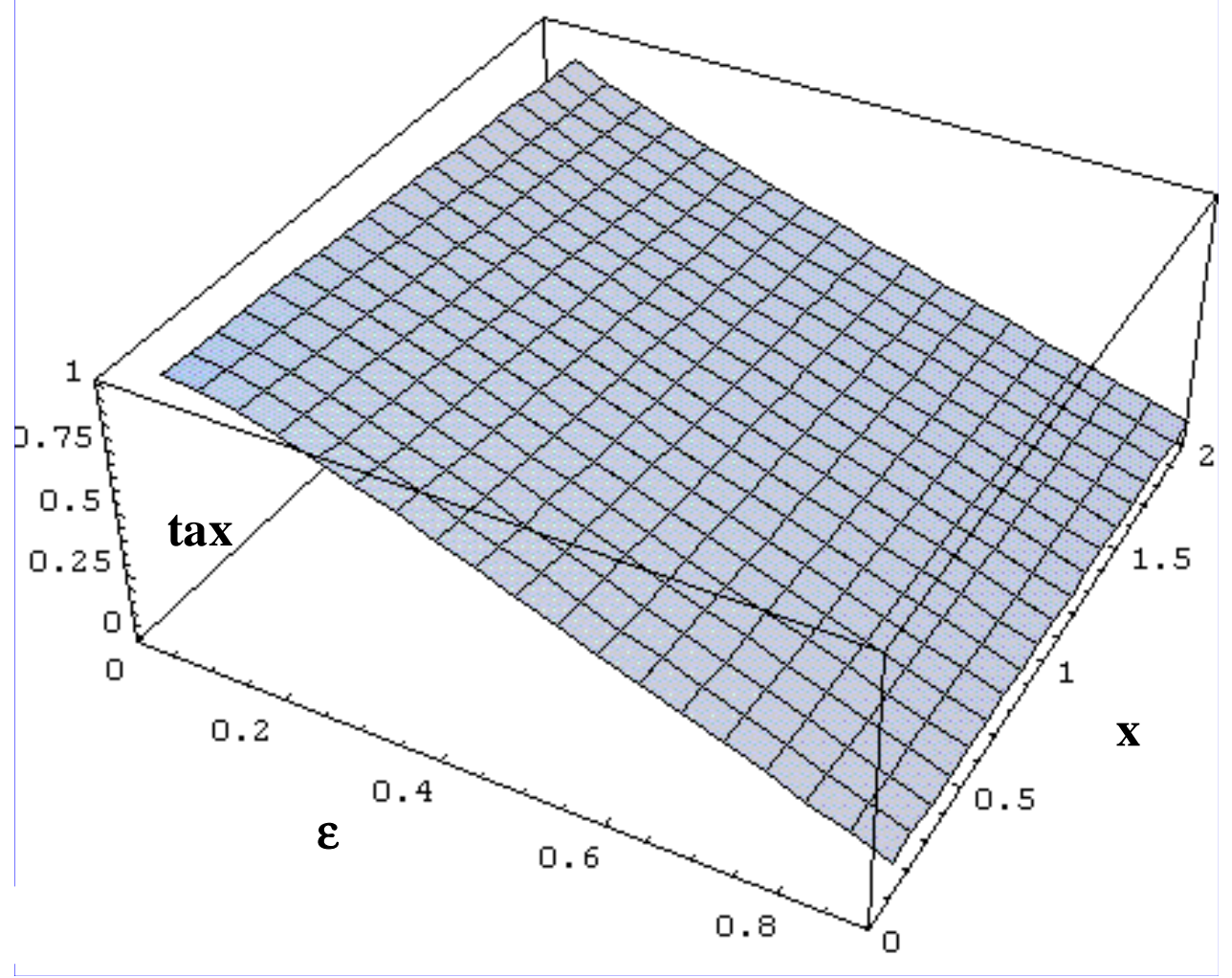

\section{Figure 1}

In the figure, we measure the difference in risk aversion between the two investors as $\mathrm{x}=\gamma_{\mathrm{L}}$ $\gamma_{\mathrm{H}}$, for $\gamma_{\mathrm{L}} \rightarrow 0$. We find that with $\mathrm{x}<.2$, the investors' risk-aversion coefficients are insufficiently different for the tax to separate the investors. The tax is also impotent below $\varepsilon$ of approximately .05. 
In Table 3, we develop some numerical examples to calculate the lowest tax rate required to induce investor $\mathrm{H}$ or $\mathrm{L}$ respectively to drop out ${ }^{17}$.

Table 3. Choice of tax rates to select out investors with different aversion to risk

\begin{tabular}{|c|c|c|c|c|c|c|c|c|c|c|}
\hline \multicolumn{4}{|c|}{ Parameter values: } & \multicolumn{3}{c|}{ H drops out } & \multicolumn{3}{c|}{ L drops out } \\
\hline $\mathbf{R}$ & $\mathbf{r}_{\mathbf{1}}^{*}$ & $\mathbf{r}_{\mathbf{2}}{ }^{*}$ & $\boldsymbol{\varepsilon}$ & $\gamma_{\mathbf{H}}$ & $\begin{array}{l}\text { Tax } \\
\text { rate }\end{array}$ & $\boldsymbol{r}_{\boldsymbol{I}}$ & $\boldsymbol{r}_{\boldsymbol{I}}(\mathbf{1 - t})$ & $\begin{array}{l}\text { Tax } \\
\text { rate }\end{array}$ & $\boldsymbol{r}_{\boldsymbol{I}}$ & $\boldsymbol{r}_{\boldsymbol{I}}(\mathbf{1 - t})$ \\
\hline 1.5 & 1.0 & 1.0 & .3 & -1.5 & .65 & 1.77 & .62 & .83 & 2.22 & .39 \\
\hline 1.5 & 1.05 & 1.05 & .3 & -1.1 & .68 & 2.11 & .67 & .80 & 2.54 & .51 \\
\hline 1.3 & 1.0 & 1.0 & .7 & -3.6 & .22 & 1.21 & .94 & .34 & 1.35 & .89 \\
\hline 1.3 & 1.05 & 1.05 & .7 & -1.5 & .27 & 1.37 & .99 & .33 & 1.45 & .98 \\
\hline 1.5 & 1.0 & 1.0 & .7 & -3.7 & .19 & 1.15 & .93 & .36 & 1.32 & .84 \\
\hline 1.5 & 1.0 & 1.1 & .7 & -3.7 & .16 & 1.13 & .95 & .35 & 1.34 & .88 \\
\hline 1.5 & 1.1 & 1.0 & .7 & -1.2 & .29 & 1.40 & .99 & .35 & 1.48 & .96 \\
\hline
\end{tabular}

Notes. In each line the interest rates are optimal for investor $L$ (who has $\gamma_{\mathrm{L}} \rightarrow 0$ ), conditional on a particular tax rate. The same rates are then "proposed" to investor $\mathrm{H}$ (who has risk aversion $\gamma_{\mathrm{H}}<\gamma_{\mathrm{L}}$, see column 5). We ensure that constraints C.1-C.3 are satisfied with this rate. We continue to raise the tax and recompute interest rates accordingly for the $\mathrm{H}$ investor until we reach her "drop out" point, characterized by the tax rate and corresponding beforeand after-tax total returns (columns 6 through 8). We continue to raise the tax rate, and recompute interest rates accordingly, until investor $\mathrm{L}$ also drops out ${ }^{18}$. See the corresponding tax rate and before- and after-tax total returns in columns 9 to 11 respectively. Also note that as the $\mathrm{L}$ investor has $\mathrm{RRA} \rightarrow 1$, the optimum $\left(\mathrm{r}_{2}\right)^{2} \rightarrow \mathrm{R}$ always.

To understand numerically the implications of Proposition 4, let us examine for instance the fourth line of Table 3. With world interest rates at 5\%, a 2 period compound return in this economy of $30 \%(\mathrm{R}=1.3)$, and a fairly high proportion of impatient investors $(70 \%)$, we see that imposing a tax rate on first-period withdrawals equal to, say, $30 \%$, is sufficient to discourage the more risk averse investors, while the less risk averse still wish to invest. The wedge between the two tax rates (the one discouraging investor $\mathrm{H}$ and the one discouraging

\footnotetext{
${ }^{17}$ Recall that the analysis has been carried out using a tax rate applied to total returns. To find the tax rate $\left(\mathrm{t}_{\mathrm{N}}\right)$ on interest rates that yields the same after-tax return as a tax $(\mathrm{t})$ on total returns, simply solve the following equation for $\mathrm{t}_{\mathrm{N}}$ : $\mathrm{r}(1-\mathrm{t})=1+\mathrm{i}\left(1-\mathrm{t}_{\mathrm{N}}\right)$.

${ }^{18}$ More precisely, to calculate the tax inducing investor $\mathrm{L}$ indifference, use the limit of equation (A.24') in the Appendix A.5, evaluated as $\gamma_{\mathrm{L}} \rightarrow 0$, i.e.: $\ln \left(\frac{\mathrm{R}}{\mathrm{r}_{1}^{*}}\right)-\varepsilon \ln \left(\frac{\mathrm{R}-\mathrm{r}_{1}^{*} \mathrm{r}_{2}^{*} \mathrm{t}}{\mathrm{r}_{1}^{*}(1-\mathrm{t})}\right)-(1-\varepsilon) \ln \left(\mathrm{r}_{2}^{*}\right)$.
} 
investor L) increases with the difference in attitudes towards risk. From the examples it is also apparent that, when the proportion of impatient investors is low (30\%), then only very high tax rates would do the job (see the first 2 rows of the table).

We can now state, without proving, a corollary of Proposition 4:

\section{Corollary.}

A tax on short-term capital inflows may reduce the range of fundamental parameter values for which a run would occur.

This follows from Proposition 4 together with Proposition 2.1 and 2.2.

\section{Discussion}

The main objection to a Chilean tax is, of course, that it may throw the baby out with the bath, i.e. discourage capital inflows tout court. So the important task in devising a tax is to fine tune it so it discourages only the most run-prone (i.e., the more risk-averse) investors. As Table 3 shows, there is room for such tuning, especially if the differences in the attitude to risk of different investor groups are wide enough.

We would also like to draw attention to one result in Proposition 3, namely that, if the relative risk aversion of the investors is "low" (strictly between 0 and 1), the imposition of a tax would increase long term (2-period) rates at the expense of short-term rates, thus reducing the degree of financial fragility even without considering a change in the composition of the investors.

Finally, there are other ways in which a Chilean tax may be effective. It may, for example, discourage herding behavior, thus helping investors to coordinate on the good rather than the bad equilibrium, as suggested by Cordella (1998). Another way is to help select the less impatient investors, that is by discouraging those with higher liquidity demand. ${ }^{19}$ Intuition suggests that these are all complementary features of the tax, hence in a more general analysis their effects would likely reinforce each other. However we leave this to future research.

\section{Conclusions}

Although capital inflows have vital importance in financing investment in emerging economies, they also play a critical role in the development of financial crises. In this paper we have focused on the role of short-term inflows intermediated by the domestic banking

\footnotetext{
${ }^{19}$ A model with this feature has been developed by Smith (1984), in the context of a closed economy.
} 
sector in the financing of domestic production in emerging economies. It is in the nature of such inflows to be subject to early withdrawals. We have modeled a situation where such withdrawals are motivated by a change in information about fundamentals: either in the domestic (a change in the productivity of invested capital) or foreign (a change in world interest rates) environment. In either case, a change in fundamentals may induce the withdrawal of foreign deposits that would otherwise have been invested for a longer period, thus activating a banking and then possibly also a currency crisis.

Our main result is that, for a given change in fundamentals, a reversal in the capital flows (and hence a financial crisis) is more likely the more risk averse are the foreign investors. Essentially, more risk averse investors demand higher first-period returns on deposits (sacrificing second period returns), making them more likely to reconsider their decision to remain invested in the emerging country after the release of unfavorable information.

We have also shown that a policy to tax early withdrawals (a tax on short-term inflows, sometimes called a "Chilean tax") may discourage the capital inflows more likely to engender fundamental runs by helping to select relatively less risk averse investors. This policy works, in our model, by forcing a steeper term structure of offered deposit rates, which in particular discourages the more risk averse investors. However, such a policy would have to be fine tuned so as not to discourage all capital inflows. In particular, we have shown, under plausible assumptions, that the range of values for which a tax on early withdrawals may help discriminate between less and more risk averse investors may well be in the range of admissible values. 


\section{REFERENCES}

Alonso, I., 1996, On avoiding bank runs, Journal of Monetary Economics, 37, 73-87

Bryant, J., 1980, A model of reserves, bank runs, and deposit insurance, Journal of Banking and Finance 4, 335-344

Calomiris, C.W and C.M. Kahn, 1991, The role of demandable debt in structuring optimal banking arrangements, American Economic Review, 497-513

Cordella, T., 1998, Can Short-term capital controls promote capital inflows?, IMF W.P. 98/131, September.

Chang, R. and A. Velasco, 1998, Financial fragility and the exchange rate regime, NBER W.P. 6469.

Chang, R. and A. Velasco, 2000, Banks, debt maturity and financial crises, Journal of International Economics, 51, 169-194

Chen, Y., 1999, Banking panics: the role of the first-come, first-served rule and information externalities, Journal of Political Economy, 107, 946-968

De Gregorio, J., S. Edwards, and R. O. Valdés, 2000, Controls on capital inflows: do they work? NBER W.P. 7645

Diamond, D.W. and P.H. Dybvig, 1983, Bank runs, deposit insurance, and liquidity, Journal of Political Economy, 91, 401-419.

Edwards, S., 1999, How effective are capital controls?, Journal of Economic Perspectives, 13, 65-84

Eichengreen, B. and A.K. Rose, 1998, Staying afloat when the wind shifts: external factors and emerging-market banking crises, CEPR D.P. 1828, April.

Furman, J. and J. Stiglitz, 1998, Economic crises: evidence and insights from east Asia, Brookings Papers on Economic Activity, 2, 1-135

Goldfajn, I. and R.O. Valdés, 1997, Capital flows and the twin crises: the role of liquidity, IMF WP/97/87, July

Jacklin and Bhatttacharya, 1988, Distinguishing panics and informationally-based bank runs: welfare and policy implications, Journal of Political Economy, 96, 568-592

Montiel P. and C. Reinhart, 1999, Do capital controls and macroeconomics policies influence the volume and composition of capital flows? Evidence from the 1990s, University of Maryland

OECD, 1999, World Economic Outlook, May.

Radelet, S. and J. Sachs, 1998, The onset of the East Asian Financial Crisis, mimeo, March.

Rodrik, D. and Velasco, 1999, Short term capital flows, NBER W.P. 7364

Smith, B., 1984, Private information, deposit interest rates, and the 'stability' of the banking system, Journal of Monetary Economics, 14, 293-317.

von Thadden, E.-L., 1997, The term-structure of investment and the banks' insurance function, European Economic Review, 7, 1355-1374. 


\section{APPENDIX}

\section{A.1 Value of $\gamma^{0}$ in section 2}

To set $r_{1}=r_{2}$, use equations (2) and (8):

$$
\left(\mathrm{r}_{2}\right)^{2}=\frac{\mathrm{R}}{1-\varepsilon}\left(1-\frac{\varepsilon \mathrm{r}_{1}}{\mathrm{r}_{1}^{*}}\right)=\frac{\mathrm{r}_{1}^{* 2}}{\left[(1-\varepsilon)\left(\frac{\mathrm{R}^{\mathrm{D}}}{\mathrm{r}_{1}^{*}}\right)^{\frac{\gamma_{0}}{\left(1-\gamma_{0}\right)}}+\varepsilon\right]^{2}}
$$

Rearrange this condition into a form easily to translate into the quadratic formula.

$$
\left[(1-\varepsilon)\left(\frac{\mathrm{R}^{\mathrm{D}}}{\mathrm{r}_{1}^{*}}\right)^{\frac{\gamma_{0}}{\left(1-\gamma_{0}\right)}}+\varepsilon\right]^{2}-\varepsilon\left[(1-\varepsilon)\left(\frac{\mathrm{R}^{\mathrm{D}}}{\mathrm{r}_{1}^{*}}\right)^{\frac{\gamma_{0}}{\left(1-\gamma_{0}\right)}}+\varepsilon\right]-\frac{\mathrm{r}_{1}^{* 2}(1-\varepsilon)}{\mathrm{R}}=0
$$

This yields the following value for $\gamma^{0}$ (the other, negative, root is imaginary):

(A.0)

$$
\gamma^{0}=\frac{\ln \left(\frac{\left(\varepsilon^{2}+\frac{4 \mathrm{r}_{1}^{* 2}(1-\varepsilon)}{\mathrm{R}}\right)^{\frac{1}{2}}-\varepsilon}{2(1-\varepsilon)}\right)}{\ln \left[\frac{\mathrm{R}}{\mathrm{r}_{1}^{*}}\right]+\ln \left(\frac{\left(\varepsilon^{2}+\frac{4 \mathrm{r}_{1}^{* 2}(1-\varepsilon)}{\mathrm{R}}\right)^{\frac{1}{2}}-\varepsilon}{2(1-\varepsilon)}\right)}
$$

\section{A.2 Proof of Proposition 2.1 (Uncertain profitability of real investment)}

First, we transform constraint C.4.1 into terms of parameters only. We then use the equation as basis to prove a more binding constraint in the case of a) higher variance and b) more risk averse investors.

Maximizing equation (4') with respect to $r_{1}$ and solving yields the following expression:

$$
\mathrm{r}_{1}=\frac{\mathrm{r}_{1}^{*}}{(1-\varepsilon)\left[\mathrm{q}\left(\frac{\mathrm{R}^{\mathrm{U}}}{\mathrm{r}_{1}^{*}}\right)^{\gamma}+(1-\mathrm{q})\left(\frac{\mathrm{R}^{\mathrm{D}}}{\mathrm{r}_{1}^{*}}\right)^{\gamma}\right]^{\frac{1}{(1-\gamma)}}+\varepsilon}
$$

Constraint C.4.1 requires satisfying the following expression:

$$
\frac{\mathrm{R}^{\mathrm{D}}}{(1-\varepsilon)}\left(\frac{\mathrm{r}_{1}^{*}-\varepsilon \mathrm{r}_{1}}{\mathrm{r}_{1}^{*}}\right)>\mathrm{r}_{1} \mathrm{r}_{2}^{*}
$$


Isolating the $r_{1}$ term in (A.2) and substituting expression equation (A.1) for $r_{1}$ yields:

(A.3)

$$
\mathrm{R}^{\mathrm{D}} \mathrm{r}_{1}^{*}>\frac{\mathrm{r}_{1}^{*}}{(1-\varepsilon)\left[\mathrm{q}\left(\frac{\mathrm{R}^{\mathrm{U}}}{\mathrm{r}_{1}^{*}}\right)^{\gamma}+(1-\mathrm{q})\left(\frac{\mathrm{R}^{\mathrm{D}}}{\mathrm{r}_{1}^{*}}\right)^{\gamma}\right]^{\frac{1}{(1-\gamma)}}+\varepsilon}\left[\mathrm{r}_{1}^{*} \mathrm{r}_{2}^{*}(1-\varepsilon)+\mathrm{R}^{\mathrm{D}} \varepsilon\right]
$$

Divide both sides by $r_{1}{ }^{*}$, multiply both sides by the denominator to obtain:

(A.4)

$$
\mathrm{R}^{\mathrm{D}}(1-\varepsilon)\left[\mathrm{q}\left(\frac{\mathrm{R}^{\mathrm{U}}}{\mathrm{r}_{1}^{*}}\right)^{\gamma}+(1-\mathrm{q})\left(\frac{\mathrm{R}^{\mathrm{D}}}{\mathrm{r}_{1}^{*}}\right)^{\gamma}\right]^{\frac{1}{(1-\gamma)}}+\mathrm{R}^{\mathrm{D}} \varepsilon>\mathrm{r}_{1}^{*} \mathrm{r}_{2}^{*}(1-\varepsilon)+\mathrm{R}^{\mathrm{D}} \varepsilon
$$

Subtract $\mathrm{R}^{\mathrm{D}} \varepsilon$ from both sides and divide by $(1-\varepsilon)$ to get:

$$
\mathrm{R}^{\mathrm{D}}\left[\mathrm{q}\left(\frac{\mathrm{R}^{\mathrm{U}}}{\mathrm{r}_{1}^{*}}\right)^{\gamma}+(1-\mathrm{q})\left(\frac{\mathrm{R}^{\mathrm{D}}}{\mathrm{r}_{1}^{*}}\right)^{\gamma}\right]^{\frac{1}{(1-\gamma)}}>\mathrm{r}_{1}^{*} \mathrm{r}_{2}^{*}
$$

Now take logs and rearrange:

$$
\operatorname{Ln}\left[\mathrm{q}\left(\frac{\mathrm{R}^{\mathrm{U}}}{\mathrm{r}_{1}^{*}}\right)^{\gamma}+(1-\mathrm{q})\left(\frac{\mathrm{R}^{\mathrm{D}}}{\mathrm{r}_{1}^{*}}\right)^{\gamma}\right]-(1-\gamma)\left[\operatorname{Ln}\left(\mathrm{r}_{1}^{*} \mathrm{r}_{2}^{*}\right)-\operatorname{Ln}\left(\mathrm{R}^{\mathrm{D}}\right)\right]>0
$$

We can now prove both parts of the Proposition.

Part a). We show that constraint C.4.1 is more likely to bind with an increase in variance.

The variance of the binomial return distribution assumed in equation (4'), is easily shown to be: $\operatorname{Var}(\mathrm{R})=\mathrm{q}(1-\mathrm{q})\left(\mathrm{R}^{\mathrm{U}}-\mathrm{R}^{\mathrm{D}}\right)^{2}$. To show that constraint C. 4.1 becomes more binding (i.e. the left hand side is reduced) we impose a mean preserving spread on $\mathrm{R}$, thus increasing its variance. That is, we increase $\mathrm{R}^{\mathrm{U}}$ and decrease $\mathrm{R}^{\mathrm{D}}$ to maintain the original mean of the distribution, $\mathrm{qR}^{\mathrm{U}}+(1-\mathrm{q}) \mathrm{R}^{\mathrm{D}}$. For this to occur, $\mathrm{dR}^{\mathrm{U}}=-\frac{(1-\mathrm{q})}{\mathrm{q}} \mathrm{dR}^{\mathrm{D}}$.

Take the derivative of (A.6) w.r.t. $\mathrm{R}^{\mathrm{D}}$ and $\mathrm{R}^{\mathrm{U}}$ and substitute out $\mathrm{dR}^{\mathrm{U}}$ according to the restriction that the mean remains the same:

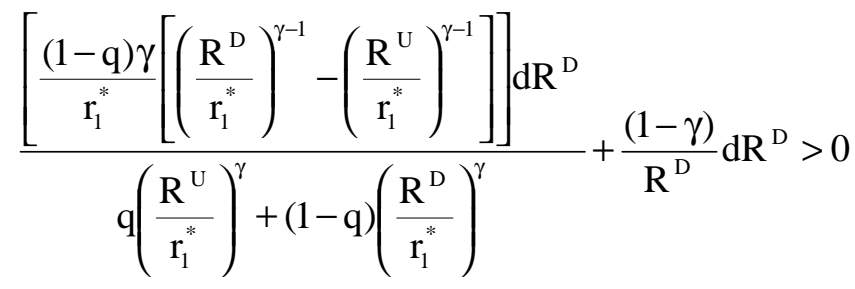

Now, combine in the numerator: 


$$
\begin{aligned}
& \underline{\left[\left(\frac{\mathrm{R}^{\mathrm{D}}}{\mathrm{r}_{1}^{*}}\right)^{\gamma-1}\left(\frac{(1-\gamma)(1-\mathrm{q})}{\mathrm{R}^{\mathrm{D}}}\left(\frac{\mathrm{R}^{\mathrm{D}}}{\mathrm{r}_{1}^{*}}\right)+\frac{(1-\mathrm{q}) \gamma}{\mathrm{r}_{1}^{*}}\right)+\left(\frac{\mathrm{R}^{\mathrm{U}}}{\mathrm{r}_{1}^{*}}\right)^{\gamma-1}\left(\left(\frac{\mathrm{R}^{\mathrm{U}}}{\mathrm{r}_{1}^{*}}\right) \frac{(1-\gamma) \mathrm{q}}{\mathrm{R}^{\mathrm{D}}}-\frac{(1-\mathrm{q}) \gamma}{\mathrm{r}_{1}^{*}}\right)\right] \mathrm{dR}^{\mathrm{D}}}>0 \\
& \mathrm{q}\left(\frac{\mathrm{R}^{\mathrm{U}}}{\mathrm{r}_{1}^{*}}\right)^{\gamma}+(1-\mathrm{q})\left(\frac{\mathrm{R}^{\mathrm{D}}}{\mathrm{r}_{1}^{*}}\right)^{\gamma}
\end{aligned}
$$

Factoring:

(A.8)

$$
\frac{\left[\left(\frac{\mathrm{R}^{\mathrm{D}}}{\mathrm{r}_{1}^{*}}\right)^{\gamma-1}(1-\mathrm{q})+\left(\frac{\mathrm{R}^{\mathrm{U}}}{\mathrm{r}_{1}^{*}}\right)^{\gamma-1}\left(\left(\frac{\mathrm{R}^{\mathrm{U}}}{\mathrm{R}^{\mathrm{D}}}\right)(1-\gamma) \mathrm{q}-(1-\mathrm{q}) \gamma\right)\right] \mathrm{dR}^{\mathrm{D}}}{\mathrm{r}_{1}^{*}\left(\mathrm{q}\left(\frac{\mathrm{R}^{\mathrm{U}}}{\mathrm{r}_{1}^{*}}\right)^{\gamma}+(1-\mathrm{q})\left(\frac{\mathrm{R}^{\mathrm{D}}}{\mathrm{r}_{1}^{*}}\right)^{\gamma}\right)}>0
$$

To understand why (A.8) is positive, note that the denominator is always $>0$. For $\gamma \leq 0$, the numerator $>0$. For the case $1>\gamma>0$, let $\mathrm{R}^{\mathrm{U}}=\mathrm{k} \mathrm{R}^{\mathrm{D}}$, where $\mathrm{k} \geq 1$. Rearrange (A.8):

(A.9)

$$
\frac{\left[\left(\frac{\mathrm{R}}{\mathrm{r}_{1}^{*}}\right)^{\gamma-1}(1-\mathrm{q})+\left(\frac{\mathrm{kR}}{\mathrm{r}_{1}^{*}}\right)^{\gamma-1}(\mathrm{kq}+\gamma(\mathrm{q}(1-\mathrm{k})-1)] \mathrm{dR}^{\mathrm{D}}\right.}{\mathrm{r}_{1}^{*}\left(\mathrm{q}\left(\frac{\mathrm{R}}{\mathrm{r}_{1}^{*}}\right)^{\gamma}+(1-\mathrm{q})\left(\frac{\mathrm{kR}}{\mathrm{r}_{1}^{*}}\right)^{\gamma}\right)}>0
$$

It is now easy to see that while the right hand term in the numerator may be negative, the term is largest in absolute value when gamma $=1$, and this is when the numerator is equal to 0 .

For example, in the simplest case set $\mathrm{R}^{\mathrm{U}}=\mathrm{R}^{\mathrm{D}}$ prior to applying the mean preserving spread, and find that equation (A.8) simplifies to:

$$
\frac{(1-\gamma) \mathrm{dR}^{\mathrm{D}}}{\mathrm{R}}>0
$$

QED

Part b) We show that an increase in risk aversion, i.e. a decline in $\gamma$, decreases the left hand side of equation (A.6), hence it makes it more difficult to satisfy constraint C.4.1.

Take the derivative of (A.6) with respect to $\gamma$.

$$
\frac{\left[\mathrm{q}\left(\frac{\mathrm{R}^{\mathrm{U}}}{\mathrm{r}_{1}^{*}}\right)^{\gamma} \ln \left(\frac{\mathrm{R}^{\mathrm{U}}}{\mathrm{r}_{1}^{*}}\right)+(1-\mathrm{q})\left(\frac{\mathrm{R}^{\mathrm{D}}}{\mathrm{r}_{1}^{*}}\right)^{\gamma} \ln \left(\frac{\mathrm{R}^{\mathrm{D}}}{\mathrm{r}_{1}^{*}}\right)\right] \mathrm{d} \gamma}{\left(\mathrm{q}\left(\frac{\mathrm{R}^{\mathrm{U}}}{\mathrm{r}_{1}^{*}}\right)^{\gamma}+(1-\mathrm{q})\left(\frac{\mathrm{R}^{\mathrm{D}}}{\mathrm{r}_{1}^{*}}\right)^{\gamma}\right)}+\left[\ln \left(\mathrm{r}_{1}^{*} \mathrm{r}_{2}^{*}\right)-\ln \left(\mathrm{R}^{\mathrm{D}}\right)\right] \mathrm{d} \gamma>0
$$

Bring terms under the common denominator and factor out the terms to the $\gamma$ power. 
(A.11)

$$
\frac{\left[\mathrm{q}\left(\frac{\mathrm{R}^{\mathrm{U}}}{\mathrm{r}_{1}^{*}}\right)^{\gamma}\left[\ln \left(\frac{\mathrm{R}^{\mathrm{U}}}{\mathrm{r}_{1}^{*}}\right)+\ln \left(\mathrm{r}_{1}^{*} \mathrm{r}_{2}^{*}\right)-\ln \left(\mathrm{R}^{\mathrm{D}}\right)\right]+(1-\mathrm{q})\left(\frac{\mathrm{R}^{\mathrm{D}}}{\mathrm{r}_{1}^{*}}\right)^{\gamma}\left[\ln \left(\frac{\mathrm{R}^{\mathrm{D}}}{\mathrm{r}_{1}^{*}}\right)+\ln \left(\mathrm{r}_{1}^{*} \mathrm{r}_{2}^{*}\right)-\ln \left(\mathrm{R}^{\mathrm{D}}\right)\right]\right] \mathrm{d} \gamma}{\left(\mathrm{q}\left(\frac{\mathrm{R}^{\mathrm{U}}}{\mathrm{r}_{1}^{*}}\right)^{\gamma}+(1-\mathrm{q})\left(\frac{\mathrm{R}^{\mathrm{D}}}{\mathrm{r}_{1}^{*}}\right)^{\gamma}\right)}>0
$$

Simplifying:

$$
\frac{\left[\mathrm{q}\left(\frac{\mathrm{R}^{\mathrm{U}}}{\mathrm{r}_{1}^{*}}\right)^{\gamma}\left[\ln \left(\frac{\mathrm{R}^{\mathrm{U}}}{\mathrm{R}^{\mathrm{D}}}\right)+\ln \left(\mathrm{r}_{2}^{*}\right)\right]+(1-\mathrm{q})\left(\frac{\mathrm{R}^{\mathrm{D}}}{\mathrm{r}_{1}^{*}}\right)^{\gamma}\left[\ln \left(\mathrm{r}_{2}^{*}\right)\right]\right] \mathrm{d} \gamma}{\left(\mathrm{q}\left(\frac{\mathrm{R}^{\mathrm{U}}}{\mathrm{r}_{1}^{*}}\right)^{\gamma}+(1-\mathrm{q})\left(\frac{\mathrm{R}^{\mathrm{D}}}{\mathrm{r}_{1}^{*}}\right)^{\gamma}\right)}>0
$$

QED

A.3 Proof of Proposition 2.2. (Uncertain value of world interest rates in period 2)

Note first that in the case that the central bank holds foreign exchange reserves, a stochastic $\mathrm{r}_{2}{ }^{*}$ will not alter the utility maximizing choice of $\mathrm{r}_{1}$ and $\mathrm{r}_{2}$ selected by agents relative to the non-stochastic case.

Constraint (C.1) will be altered at time 0 , but the assumption $\mathrm{R}>\mathrm{r}_{1}{ }^{*} \mathrm{r}_{2}{ }^{*}$ ensures the constraint does not bind to the extent that the expected value in the stochastic case is the same as the value of $\mathrm{r}_{2}{ }^{*}$ in the deterministic case.

In part a), we show that constraint (C.4.2) is more likely to bind with a higher variance of $r_{2}$. In part b) we show it is more likely to bind when investors are more risk-averse.

Constraint C.4.2 requires satisfying the following expression:

$$
\frac{\mathrm{R}}{(1-\varepsilon)}\left(\frac{\mathrm{r}_{1}^{*}-\varepsilon \mathrm{r}_{1}}{\mathrm{r}_{1}^{*}}\right)>\mathrm{r}_{1} \mathrm{r}_{2}^{\mathrm{U}^{*}}
$$

Isolating the $r_{1}$ term in (A.13) and substituting expression equation (A.1) for $r_{1}$ yields:

$$
\mathrm{Rr}_{1}^{*}>\frac{\mathrm{r}_{1}^{*}}{(1-\varepsilon)\left(\frac{\mathrm{R}}{\mathrm{r}_{1}^{*}}\right)^{\frac{\gamma}{(1-\gamma)}}+\varepsilon}\left[\mathrm{r}_{1}^{*} \mathrm{r}_{2}^{\mathrm{U}^{*}}(1-\varepsilon)+\mathrm{R} \varepsilon\right]
$$

Divide both sides by $r_{1}{ }^{*}$, multiply both sides by the denominator to obtain:

$$
\mathrm{R}(1-\varepsilon)\left(\frac{\mathrm{R}}{\mathrm{r}_{1}^{*}}\right)^{\frac{\gamma}{(1-\gamma)}}+\mathrm{R} \varepsilon>\left[\mathrm{r}_{1}^{*} \mathrm{r}_{2}^{\mathrm{U}^{*}}(1-\varepsilon)+\mathrm{R} \varepsilon\right]
$$

Subtract Re from both sides and divide by $(1-\varepsilon)$ to get: 


$$
\mathrm{R}\left(\frac{\mathrm{R}}{\mathrm{r}_{1}^{*}}\right)^{\frac{\gamma}{(1-\gamma)}}>\left[\mathrm{r}_{1}^{*} \mathrm{r}_{2}^{\mathrm{U}^{*}}\right]
$$

Divide both sides by $\mathrm{r}_{1}{ }^{*}$ :

$$
\left(\frac{\mathrm{R}}{\mathrm{r}_{1}^{*}}\right)^{\frac{1}{(1-\gamma)}}>\mathrm{r}_{2}^{\mathrm{U}^{*}}
$$

Part a). We show below that constraint C.4.2 is more likely to bind with an increase in variance.

The variance of the binomial return distribution implicit in equation (8), is easily shown to be: $\operatorname{Var}\left(r_{2}^{*}\right)=p(1-p)\left(r_{2}^{U}-r_{2}^{D}\right)^{2}$. By observation, (A.17) becomes more binding with a higher $\mathrm{r}_{2}{ }^{\mathrm{U}}$ that would be implicit in a mean preserving spread which increased the variance of $\mathrm{r}_{2}{ }^{*}$.

QED

Part b) We show that an increase in risk aversion, i.e. a decline in $\gamma$, decreases the left hand side of equation (A.17), i.e. makes it more difficult to satisfy constraint C.4.2.

Take the derivative of (A.17) with respect to $\gamma$.

$$
\frac{\left(\frac{\mathrm{R}}{\mathrm{r}_{1} *}\right)^{\frac{1}{(1-\gamma)}} \ln \left(\frac{\mathrm{R}}{\mathrm{r}_{1} *}\right)}{(1-\gamma)^{2}}>0
$$

QED

\section{A.4 Proof of Proposition 3 (Imposition of a Chilean-type tax)}

\section{Part i. Derivation of the equilibrium contract in presence of taxes.}

Imposing a Chilean type tax alters the balance of payments and balance sheet constraints. First, note that flows in period 0 are unaffected, thus (1.1) is unchanged. In period 1, the gross foreign exchange earnings from investing reserves abroad in period 0 are divided between the (net of tax) payment to impatient investors and the tax payment to the government, expressed in the equation ${ }^{20} r_{1}^{*} F_{0}=\varepsilon r_{1} D_{0} t+\varepsilon r_{1} D_{0}(1-t)$

Finally, in period 2, the project yields export goods. The proceeds of this sale reimburses (as in the base case) patient investors. In this case, however, tax receipts augment patient investors' returns. This implies that equation (1.3) changes:

$$
\mathrm{RL}_{0}=\left(\mathrm{r}_{2}^{2}\right)(1-\varepsilon) \mathrm{D}_{0}-\varepsilon \mathrm{r}_{2}^{*} \operatorname{tr}_{1} \mathrm{D}_{0}
$$

\footnotetext{
${ }^{20}$ Note that this is identical to equation (1.2) in the text; i.e. the balance sheet and balance of payments restrictions remain identical. Note also that since the government invests the tax revenue abroad at period 1 it will earn foreign riskless rate $r_{2} *$ affecting period 2 accounts.
} 
where the second term on the right hand side is the return from investing abroad the tax revenue from impatient investors.

Combining equations (1.1), (1.2), and (1.3') and solving for $\mathrm{r}_{2}^{2}$

$$
\mathrm{r}_{2}^{2}=\frac{\mathrm{R}}{(1-\varepsilon)}-\frac{\varepsilon \mathrm{r}_{1}}{(1-\varepsilon) \mathrm{r}_{1}^{*}}\left[\mathrm{R}-\mathrm{r}_{1}^{*} \mathrm{r}_{2}^{*} \mathrm{t}\right]
$$

Note this resource constraint reflects that a higher $r_{2} *$ increases the return on the government tax revenue and hence the return to patient investors.

Maximization of expected utility now requires to solve the following:

$$
\operatorname{Max}\left[\varepsilon U\left(r_{1}(1-t)\right)+(1-\varepsilon) U\left(\frac{R}{(1-\varepsilon)}-\frac{\varepsilon r_{1}}{(1-\varepsilon) r_{1}^{*}}\left[R-r_{1}^{*} r_{2}^{*} t\right]\right)\right]
$$

In the case of CRRA preferences, the solution to this problem is obtained by satisfying the first order condition:

$$
\left(r_{1}(1-t)\right)^{\gamma-1}(1-t)+\left(\frac{R}{(1-\varepsilon)}-\frac{\varepsilon r_{1}}{(1-\varepsilon) r_{1}^{*}}\left[R-r_{1}^{*} r_{2}^{*} t\right]\right)^{\gamma-1}\left[r_{1}^{*} t-\frac{R}{r_{1}^{*}}\right]=0
$$

Solving this equation for $\mathrm{r}_{1}$ yields:

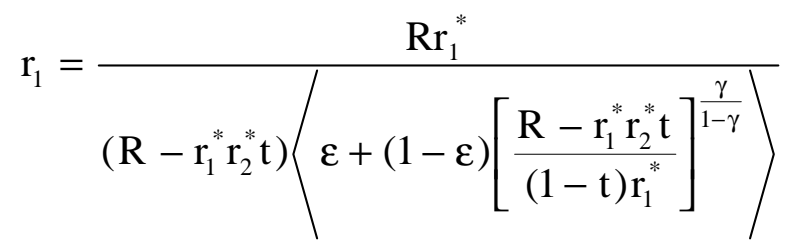

\section{Part ii. Net-of-tax $r_{1}$ declines with a higher tax}

First, take the partial derivative of $r_{1}(1-t)$ w.r.t. $t$ to show that net of tax $r 1$ decreases:

$$
\frac{\partial r_{1}(1-t)}{\partial t}=\frac{\left.\operatorname{Rr}_{1}^{*}(1-t)\left[r_{1}^{*} r_{2}^{*} \varepsilon+(1-\varepsilon)\left[\frac{\left(R-r_{1}^{*} r_{2}^{*} t\right)}{(1-t) r_{1}^{*}}\right]^{\frac{\gamma}{1-\gamma}} / r_{1}^{*} r_{2}^{*}-\frac{\gamma}{1-\gamma} \frac{\left(R-r_{1}^{*} r_{2}^{*}\right)}{(1-t)}\right\rangle\right]}{\left[\left(R-r_{1}^{*} r_{2}^{*} t\right)\left(\varepsilon+(1-\varepsilon)\left[\frac{\left(R-r_{1}^{*} r_{2}^{*} t\right)}{(1-t) r_{1}^{*}}\right]^{\frac{\gamma}{1-\gamma}} /\right]^{2}\right.}-\frac{R_{r_{1}^{*}}^{*}}{\left(R-r_{1}^{*} r_{2}^{*} t\right)\left(\varepsilon+(1-\varepsilon)\left[\frac{\left(R-r_{1}^{*} r_{2}^{*} t\right)}{(1-t) r_{1}^{*}}\right]^{\frac{\gamma}{1-\gamma}}\right]}
$$

Raising the second term to a common denominator, we find after simplifying:

$$
\frac{\partial \mathrm{r}_{1}(1-\mathrm{t})}{\partial \mathrm{t}}=\frac{\operatorname{Rr}_{1}^{*}\left(\left[\mathrm{r}_{1}^{*} \mathrm{r}_{2}^{*} \varepsilon+(1-\mathrm{t})(1-\varepsilon)\left[\frac{\left(\mathrm{R}-\mathrm{r}_{1}^{*} \mathrm{r}_{2}^{*} \mathrm{t}\right)}{(1-\mathrm{t}) \mathrm{r}_{1}^{*}}\right]^{\frac{\gamma}{1-\gamma}}\left\langle\frac{\gamma}{1-\gamma} \frac{\left(\mathrm{R}-\mathrm{r}_{1}^{*} \mathrm{r}_{2}^{*}\right)}{(1-\mathrm{t})}\right)\right]-\left[\mathrm{R} \varepsilon+\mathrm{R}(1-\varepsilon)\left[\frac{\left(\mathrm{R}-\mathrm{r}_{1}^{*} \mathrm{r}_{2}^{*} \mathrm{t}\right)}{(1-\mathrm{t}) \mathrm{r}_{1}^{*}}\right]^{\frac{\gamma}{1-\gamma}}\right]\right)}{\left.\left[\left(\mathrm{R}-\mathrm{r}_{1}^{*} \mathrm{r}_{2}^{*} \mathrm{t}\right) / \varepsilon+(1-\varepsilon)\left[\frac{\left(\mathrm{R}-\mathrm{r}_{1}^{*} \mathrm{r}_{2}^{*} \mathrm{t}\right)}{(1-\mathrm{t}) \mathrm{r}_{1}^{*}}\right]^{\frac{\gamma}{1-\gamma}}\right\rangle\right]^{2}}
$$


Factoring the term in exponents and simplifying:

$$
\frac{\partial r_{1}(1-t)}{\partial t}=\frac{R_{1}^{*}\left\langle(1-\varepsilon)\left[\frac{\left(R-r_{1}^{*} r_{2}^{*} t\right)}{(1-t) r_{1}^{*}}\right]^{\frac{\gamma}{1-\gamma}}\left(r_{1}^{*} r_{2}^{*}-\frac{\gamma}{1-\gamma}\left(R-r_{1}^{*} r_{2}^{*}\right)-R\right)+\varepsilon\left[r_{1}^{*} r_{2}^{*}-R\right]\right\rangle}{\left[\left(R-r_{1}^{*} r_{2}^{*} t\right)\left(\varepsilon+(1-\varepsilon)\left[\frac{\left(R-r_{1}^{*} r_{2}^{*} t\right)}{(1-t) r_{1}^{*}}\right]^{\frac{\gamma}{1-\gamma}}\right\rangle\right]^{2}}
$$

Further simplifying:

$$
\frac{\partial r_{1}(1-t)}{\partial t}=\frac{-R_{1}^{*}\left(R-r_{1}^{*} r_{2}^{*}\right)\left(\frac{(1-\varepsilon)}{(1-\gamma)}\left[\frac{\left(R-r_{1}^{*} r_{2}^{*} t\right)}{(1-t) r_{1}^{*}}\right]^{\frac{\gamma}{1-\gamma}}+\varepsilon\right\rangle}{\left.\left[\left(R-r_{1}^{*} r_{2}^{*} t\right) / \varepsilon+(1-\varepsilon)\left[\frac{\left(R-r_{1}^{*} r_{2}^{*} t\right)}{(1-t) r_{1}^{*}}\right]^{\frac{\gamma}{1-\gamma}}\right\rangle\right]^{2}}
$$

This expression is clearly negative for $\gamma<1$.

Part iii. Partial derivative of $r_{2}^{2}$ and of $\left(r_{2}-r_{1}(1-t)\right)$ with respect to a change in tax rate.

Substitute eq. ( $\left.8^{\prime}\right)$ into (2') for the equilibrium $r_{2}^{2}$ in a world with taxes. Simplifying:

$$
\mathrm{r}_{2}{ }^{2}=\frac{\mathrm{R}}{\varepsilon\left(\frac{\left(\mathrm{R}-\mathrm{r}_{1}^{*} \mathrm{r}_{2}^{*} \mathrm{t}\right)}{\mathrm{r}_{1}^{*}(1-\mathrm{t})}\right)^{\frac{\gamma}{(\gamma-1)}}+(1-\varepsilon)}
$$

And taking the partial derivative for use in part iv below:

$$
\frac{\partial \mathrm{r}_{2}^{2}}{\partial \mathrm{t}}=\frac{\varepsilon\left(\frac{\left(\mathrm{R}-\mathrm{r}_{1}^{*} \mathrm{r}_{2}^{*} \mathrm{t}\right)}{\mathrm{r}_{1}^{*}(1-\mathrm{t})}\right)^{\frac{1}{(\gamma-1)}} \mathrm{R} \gamma\left(\mathrm{R}-\mathrm{r}_{1}^{*} \mathrm{r}_{2}^{*}\right)}{(1-\gamma) \mathrm{r}_{1}^{*}(1-\mathrm{t})^{2}\left[\varepsilon\left(\frac{\left(\mathrm{R}-\mathrm{r}_{1}^{*} \mathrm{r}_{2}^{*} \mathrm{t}\right)}{\mathrm{r}_{1}^{*}(1-\mathrm{t})}\right)^{\frac{\gamma}{(\gamma-1)}}+(1-\varepsilon)\right]^{2}}
$$

where we observe that, for the case where $\gamma<0$, this derivative is also $<0$, whereas it is positive for the case of where $0<\gamma<1$.

As regards the derivative of the after-tax term structure slope, we are unable to provide a signed derivative, however, we have computed the solution within the space of reasonable parameter values and have always find that an increase in tax will increase the slope of the term structure. Numerical simulations using Mathematica are available upon request. 


\section{Part iv. Investors may be discouraged if a tax is applied.}

An investor may be discouraged if for any parameter values, the imposition of a tax brings any constraint to become more binding. We show that if a tax is imposed for any given parameter values, C. 1 becomes more binding. That is, $\frac{\partial(\mathrm{C} 1)}{\partial \mathrm{t}}<0$, where:

$$
\mathrm{Cl}=\frac{\varepsilon}{\gamma}\left(\mathrm{r}_{1}(1-\mathrm{t})\right)^{\gamma}+\frac{(1-\varepsilon)}{\gamma}\left(\mathrm{r}_{2}^{2}\right)^{\gamma}-\frac{\mathrm{r}_{1}^{* \gamma}}{\gamma}\left(\varepsilon+(1-\varepsilon) \mathrm{r}_{2}^{* \gamma}\right)
$$

This will be true if

$$
\frac{\partial \mathrm{C} 1}{\partial \mathrm{t}}=\varepsilon\left(\mathrm{r}_{1}(1-\mathrm{t})\right)^{\gamma-1} \frac{\partial \mathrm{r}_{1}(1-\mathrm{t})}{\partial \mathrm{t}}+(1-\varepsilon)\left(\mathrm{r}_{2}^{2}\right)^{\gamma-1} \frac{\partial \mathrm{r}_{2}^{2}}{\partial \mathrm{t}}<0
$$

Since both (A.19) and (A.21) are negative, (A.22) is also negative.

\section{QED}

A.5 Proof of Proposition 4 (A Chilean tax selects less-risk averse investors)

The proof is in 3 parts:

i. For given interest rates, $r_{1}{ }^{*}, r_{2}{ }^{*}, R$, a given proportion of impatient investors, $\varepsilon$, and two investors with given levels of risk aversion, $\gamma_{\mathrm{H}}<\gamma_{\mathrm{L}}<0$, we seek a level of tax, that satisfies constraint C.1 for investor L, but does NOT satisfy C. 1 for investor $\mathrm{H}$.

ii. For these parameters, we show that in the absence of a tax, the $\mathrm{H}$ investor would accept the contract, i.e. when $\mathrm{t}=0$, constraint C. 1 is satisfied for investor $\mathrm{H}$.

iii. We then show that no investor will be influenced by constraints C.2 or C.3, so we do not analyze these constraints.

Part $i$. There exists a tax rate $t$ simultaneously solving $C .1$ for investor $L$, but not for investor $H$.

We consider a contract offering rates $r_{1}$ and $r_{2}$ that would be the optimal choice of the $L$ investor as if she were the only investor. These rates are taken as a given by the $\mathrm{H}$ person in considering whether to accept the contract or not. That is, constraint C.1 is weighted by the risk-aversion coefficient of investor $\mathrm{H}$.

A tax rate, t, to keep H out must then satisfy (insert in C.1 equations (2') and (8'), equilibrium $r_{1}$ and $r_{2}$ that optimally satisfy the L investor): 


$$
\frac{\varepsilon}{\gamma_{\mathrm{H}}}\left(\frac{(1-\mathrm{t}) \mathrm{Rr}_{1}^{*}}{\left(\mathrm{R}-\mathrm{r}_{1}^{*} \mathrm{r}_{2}^{*} \mathrm{t}\right)\left\{\varepsilon+(1-\varepsilon)\left[\frac{\left(\mathrm{R}-\mathrm{r}_{1}^{*} \mathrm{r}_{2}^{*} \mathrm{t}\right)}{\mathrm{r}_{1}^{*}(1-\mathrm{t})}\right]^{\frac{\gamma_{\mathrm{L}}}{1-\gamma_{\mathrm{L}}}}\right\}}\right)^{\gamma_{\mathrm{H}}}
$$

$$
+\frac{1-\varepsilon}{\gamma_{\mathrm{H}}}\left[\frac{\mathrm{R}}{1-\varepsilon}-\frac{\left(\mathrm{R}-\mathrm{r}_{1}^{*} \mathrm{r}_{2}^{*} \mathrm{t}\right) \varepsilon}{\mathrm{r}_{1}^{*}(1-\varepsilon)}\left[\frac{\mathrm{Rr}_{1}^{*}}{\left(\mathrm{R}-\mathrm{r}_{1}^{*} \mathrm{r}_{2}^{*} \mathrm{t}\right)\left\{\varepsilon+(1-\varepsilon)\left[\frac{\left.\left(\mathrm{R}-\mathrm{r}_{1}^{*} \mathrm{r}_{2}^{*} \mathrm{t}\right)\right]^{\frac{\gamma_{\mathrm{L}}}{1-\gamma_{\mathrm{L}}}}}{\mathrm{r}_{1}^{*}(1-\mathrm{t})}\right]\right.}\right]\right]^{\gamma^{\gamma_{\mathrm{H}}}}<\frac{\mathrm{r}_{1}^{*} \gamma_{\mathrm{H}}\left[\varepsilon+(1-\varepsilon) \mathrm{r}_{2} \gamma_{\mathrm{H}}\right]}{\gamma_{\mathrm{H}}}
$$

Simplify the second term and create new variables A and B, where:

$$
A=\frac{\left(R-r_{1}^{*} r_{2}^{*} t\right)}{(1-t) r_{1}^{*}} \quad \text { and } \quad B=\frac{\gamma_{L}}{\left(1-\gamma_{L}\right)}
$$

to obtain the following equation:

$$
\frac{\varepsilon}{\gamma_{\mathrm{H}}}\left(\frac{(1-\mathrm{t}) \mathrm{Rr}_{1}^{*}}{\left(\mathrm{R}-\mathrm{r}_{1}^{*} \mathrm{r}_{2}^{*} \mathrm{t}\right)\left\{\varepsilon+(1-\varepsilon) \mathrm{A}^{\mathrm{B}}\right\}}\right)^{\gamma_{\mathrm{H}}}+\frac{1-\varepsilon}{\gamma_{\mathrm{H}}}\left(\frac{\mathrm{R}}{1-\varepsilon}\right)^{\gamma_{\mathrm{H}}}\left[\frac{(1-\varepsilon) \mathrm{A}^{\mathrm{B}}}{\left\{\varepsilon+(1-\varepsilon) \mathrm{A}^{\mathrm{B}}\right\}}\right]^{\gamma_{\mathrm{H}}}<\frac{\mathrm{r}_{1}^{*^{*} \gamma_{\mathrm{H}}}\left[\varepsilon+(1-\varepsilon) \mathrm{r}_{2}^{*} \gamma_{\mathrm{H}}\right]}{\gamma_{\mathrm{H}}}
$$

Divide both sides by $\gamma_{\mathrm{H}}$, factor the term from the left hand side to get:

$$
\left(\frac{R}{\left\{\varepsilon+(1-\varepsilon) A^{B}\right\}}\right)^{\gamma_{\mathrm{H}}}\left[\varepsilon\left(\frac{(1-t) r_{1}^{*}}{\left(R-r_{1}^{*} r_{2}^{*} t\right)}\right)^{\gamma_{\mathrm{H}}}+(1-\varepsilon)\left[\frac{(1-\varepsilon) A^{B}}{(1-\varepsilon)}\right]^{\gamma_{\mathrm{H}}}\right]>r_{1}^{* \gamma_{\mathrm{H}}}\left[\varepsilon+(1-\varepsilon) r_{2}^{* \gamma_{\mathrm{H}}}\right]
$$

Simplifying, we establish the condition for "H out":

$$
\frac{\varepsilon \mathrm{A}^{-\gamma_{\mathrm{H}}}+(1-\varepsilon) \mathrm{A}^{\mathrm{B} \gamma_{\mathrm{H}}}}{\left[\varepsilon+(1-\varepsilon) \mathrm{A}^{\mathrm{B}}\right]^{\gamma_{\mathrm{H}}}}>\left(\frac{\mathrm{R}}{\mathrm{r}_{1}^{*}}\right)^{-\gamma_{\mathrm{H}}}\left[\varepsilon+(1-\varepsilon) \mathrm{r}_{2}^{* \gamma_{\mathrm{H}}}\right]
$$

We use similar steps to obtain the condition required for $\mathrm{L}$ to accept the contract ("L in"):

$$
\frac{\varepsilon \mathrm{A}^{-\gamma_{\mathrm{L}}}+(1-\varepsilon) \mathrm{A}^{\mathrm{B} \gamma_{\mathrm{L}}}}{\gamma_{\mathrm{L}}\left[\varepsilon+(1-\varepsilon) \mathrm{A}^{\mathrm{B}}\right]^{\gamma_{\mathrm{L}}}} \geq\left(\frac{\mathrm{R}}{\mathrm{r}_{1}^{*}}\right)^{-\gamma_{\mathrm{L}}} \frac{\left[\varepsilon+(1-\varepsilon) \mathrm{r}_{2}^{* \gamma_{\mathrm{L}}}\right]}{\gamma_{\mathrm{L}}}
$$

Notice that variable $A$ is increasing in the tax rate. Notice also that if $\mathrm{R}=\mathrm{r}_{1} * \mathrm{r}_{2} *$ (the lowest real return by assumption A.1), $A=\frac{R}{r_{1}^{*}}$, independent of the tax. That is, a tax can have no effect in this circumstance since both investors have C.1 constraints at the point of binding. 
Now define, for later convenience, $\gamma_{H}=\left(\gamma_{L}-x\right)$, where $x$ is a positive constant. Rewriting

$$
\frac{\varepsilon A^{-\gamma_{L}} A^{x}+(1-\varepsilon) A^{B \gamma_{L}} A^{-B x}}{\left[\varepsilon+(1-\varepsilon) A^{B}\right]^{\gamma_{L}}\left[\varepsilon+(1-\varepsilon) A^{B}\right]^{-x}}>\left(\frac{R}{r_{1}^{*}}\right)^{-\gamma_{L}}\left(\frac{R}{r_{1}^{*}}\right)^{x}\left[\varepsilon+(1-\varepsilon) r_{2}^{* \gamma_{L}} r_{2}^{*-x}\right]
$$

\section{Rearranging:}

$$
\frac{\varepsilon A^{-\gamma_{L}} A^{x}+(1-\varepsilon) A^{B \gamma_{L}} A^{-B x}}{\left[\varepsilon+(1-\varepsilon) A^{B}\right]^{-x}\left(\frac{R}{r_{1}^{*}}\right)^{x}\left[\varepsilon+(1-\varepsilon) r_{2}^{* \gamma_{L}} r_{2}^{*-x}\right]}>\left(\frac{R}{r_{1}^{*}}\right)^{-\gamma_{L}}\left[\varepsilon+(1-\varepsilon) A^{B}\right]^{\gamma_{L}}
$$

Now rearrange (A.24) so the right hand side is identical to that of equation (A.25):

$$
\frac{\varepsilon A^{-\gamma_{L}}+(1-\varepsilon) A^{B \gamma_{L}}}{\left[\varepsilon+(1-\varepsilon) r_{2}^{* \gamma_{\mathrm{L}}}\right]} \leq\left(\frac{\mathrm{R}}{\mathrm{r}_{1}^{*}}\right)^{-\gamma_{\mathrm{L}}}\left[\varepsilon+(1-\varepsilon) \mathrm{A}^{\mathrm{B}}\right]^{\gamma_{\mathrm{L}}}
$$

Thus, to separate out investors having relatively risk-averse preferences, we require a tax rate $\mathrm{t}$ satisfying simultaneously (A.23) and (A.24'), i.e. to find a tax rate $t_{0}$ solving the inequality:

$$
\frac{\varepsilon \mathrm{A}^{-\gamma_{\mathrm{L}}}+(1-\varepsilon) \mathrm{A}^{\mathrm{B} \gamma_{\mathrm{L}}}}{\left[\varepsilon+(1-\varepsilon) \mathrm{r}_{2}^{* \gamma_{\mathrm{L}}}\right]}<\frac{\varepsilon \mathrm{A}^{-\gamma_{\mathrm{L}}} \mathrm{A}^{\mathrm{x}}+(1-\varepsilon) \mathrm{A}^{\mathrm{B} \gamma_{\mathrm{L}}} \mathrm{A}^{-\mathrm{Bx}}}{\left[\varepsilon+(1-\varepsilon) \mathrm{A}^{\mathrm{B}}\right]^{-\mathrm{x}}\left(\frac{\mathrm{R}}{\mathrm{r}_{1}^{*}}\right)^{\mathrm{x}}\left[\varepsilon+(1-\varepsilon) \mathrm{r}_{2}^{* \gamma_{\mathrm{L}}} \mathrm{r}_{2}^{*-\mathrm{x}}\right]}
$$

In order to simplify, assume $\lim \gamma_{L} \rightarrow 0($ which $=>B \rightarrow 0)$ :

$$
\frac{\varepsilon+(1-\varepsilon)}{[\varepsilon+(1-\varepsilon)]}<\frac{\varepsilon A^{\mathrm{x}}+(1-\varepsilon)}{[\varepsilon+(1-\varepsilon)]^{-\mathrm{x}}\left(\frac{\mathrm{R}}{\mathrm{r}_{1}^{*}}\right)^{\mathrm{x}}\left[\varepsilon+(1-\varepsilon) \mathrm{r}_{2}^{{ }^{*-\mathrm{x}}}\right]}
$$

or:

(A.27)

$$
\left(\frac{\mathrm{R}}{\mathrm{r}_{1}^{*}}\right)^{\mathrm{x}}\left[\varepsilon+(1-\varepsilon) \mathrm{r}_{2}^{*-\mathrm{x}}\right]<\varepsilon \mathrm{A}^{\mathrm{x}}+(1-\varepsilon)
$$

Now decompose $\mathrm{A}$ and solve for $\mathrm{t}_{0}$ :

$$
\frac{\mathrm{R}^{\mathrm{x}}\left[\varepsilon \mathrm{r}_{2}^{* \mathrm{x}}+(1-\varepsilon)\right]-(1-\varepsilon) \mathrm{r}_{1}^{*} \mathrm{x}_{2}^{* \mathrm{x}}}{\mathrm{r}_{1}^{*} \mathrm{x}_{2}^{* \mathrm{x}}}<\varepsilon\left[\frac{\left(\mathrm{R}-\mathrm{r}_{1}{ }^{*} \mathrm{r}_{2}^{*} \mathrm{t}_{0}\right)}{\left(1-\mathrm{t}_{0}\right) \mathrm{r}_{1}^{*}}\right]^{\mathrm{X}}
$$

Now define:

$$
\mathrm{C}=\frac{\varepsilon \mathrm{r}_{2}^{* \mathrm{x}} \mathrm{R}^{\mathrm{x}}+\left[(1-\varepsilon)\left\langle\mathrm{R}^{\mathrm{x}}-\mathrm{r}_{1}^{* \mathrm{x}} \mathrm{r}_{2}^{* \mathrm{x}}\right\rangle\right]}{\varepsilon \mathrm{r}_{1}^{* \mathrm{x}} \mathrm{r}_{2}^{* \mathrm{x}}}
$$


and solve (A.28) for $\mathrm{t}_{0}$ :

$$
\frac{C^{1 / x}-\frac{R}{r_{1}^{*}}}{C^{1 / x}-r_{2}^{*}}<t_{0}
$$

Now, obviously $\mathrm{C}>1$, implying $\mathrm{t}_{0}<1$ for some parameter values. Thus (A.29) gives the condition for a tax that simultaneously satisfies C. 1 for $\mathrm{L}$ but not for $\mathrm{H}$.

Note that since we use the C. 1 constraint for the $\mathrm{H}$ investor as an equality, $\mathrm{t}_{0}$ gives the lowest tax that makes the contract unacceptable to the $\mathrm{H}$ investor. It does not inform about the maximum tax for which investor $\mathrm{L}$ accepts the contract. We examine this issue in the text.

We now turn to the next part of the proof.

Part ii. The $H$ investor rejecting the above contract would accept the same contract in the absence of a tax.

Consider again equation (A.23) and set $\mathrm{t}=0$. Note $A=\frac{R}{r_{1}^{*}}$ in this case. It implies the $\mathrm{H}$ investor has an incentive to participate if:

$$
\frac{\varepsilon\left(\frac{\mathrm{R}}{\mathrm{r}_{1}^{*}}\right)^{-\gamma_{\mathrm{H}}}+(1-\varepsilon)\left(\frac{\mathrm{R}}{\mathrm{r}_{1}^{*}}\right)^{\mathrm{B} \gamma_{\mathrm{H}}}}{\gamma_{\mathrm{H}}\left[\varepsilon+(1-\varepsilon)\left(\frac{\mathrm{R}}{\mathrm{r}_{1}^{*}}\right)^{\mathrm{B}}\right]^{\gamma_{\mathrm{H}}}}>\left(\frac{\mathrm{R}}{\mathrm{r}_{1}^{*}}\right)^{-\gamma_{\mathrm{H}}} \frac{\left[\varepsilon+(1-\varepsilon) \mathrm{r}_{2}^{* \gamma_{\mathrm{H}}}\right]}{\gamma_{\mathrm{H}}}
$$

Since $\gamma_{\mathrm{H}}<0$ and $\gamma_{\mathrm{L}} \rightarrow 0 \Rightarrow \mathrm{B} \rightarrow 0$, rewrite (A.30) as:

$$
\frac{\varepsilon\left(\frac{\mathrm{R}}{\mathrm{r}_{1}^{*}}\right)^{-\gamma_{\mathrm{H}}}+(1-\varepsilon)}{[\varepsilon+(1-\varepsilon)]^{\gamma_{\mathrm{H}}}}<\left(\frac{\mathrm{R}}{\mathrm{r}_{1}^{*}}\right)^{-\gamma_{\mathrm{H}}}\left[\varepsilon+(1-\varepsilon) \mathrm{r}_{2}^{*_{\mathrm{H}}}\right]
$$

Simplifying:

$$
\text { (A.31) } \quad\left(\frac{\mathrm{R}}{\mathrm{r}_{1}^{*}}\right)^{\gamma_{\mathrm{H}}}<\mathrm{r}_{2}^{* \gamma_{\mathrm{H}}}
$$

This is true by assumption (A.1).

\section{QED}

Part iii. Constraints C.2 and C.3 never bind with the parameter values associated with the contract of part $i$.

In the case a tax is imposed, constraint C. 2 "do not go short" must be $>0$.

$$
\mathrm{C} 2=\frac{\varepsilon}{\gamma}\left(\mathrm{r}_{1}(1-\mathrm{t})\right)^{\gamma}+\frac{(1-\varepsilon)}{\gamma}\left(\mathrm{r}_{2}^{2}\right)^{\gamma}-\frac{\varepsilon}{\gamma}\left(\mathrm{r}_{1}(1-\mathrm{t})\right)^{\gamma}-\frac{(1-\varepsilon)}{\gamma}\left(\mathrm{r}_{1}(1-\mathrm{t})\right)^{2 \gamma}
$$


It can be easily shown that the above will be satisfied so long as the spread is positive. The investor may rather invest in short-term deposits if the tax causes the spread to become negative. Simplify and insert equilibrium contract values, equations (A.20) and (8'), where the latter is multiplied by (1-t):

$$
\mathrm{r}_{2}^{2}-\left(\mathrm{r}_{1}(1-\mathrm{t})\right)^{2}=\left[\frac{\mathrm{R}}{\varepsilon \mathrm{A}^{\frac{\gamma}{(\gamma-1)}}+(1-\varepsilon)}\right]-\left[\frac{\mathrm{R}}{\mathrm{A}\left(\varepsilon+(1-\varepsilon) \mathrm{A}^{\frac{\gamma}{(1-\gamma)}}\right)}\right]^{2}
$$

where $\quad A=\left[\frac{R-r_{1}^{*} r_{2}^{*} t}{(1-t) r_{1}^{*}}\right]$

Using the assumptions from part $i$. above, that the contract offers an interest rate combination set optimally for an L investor with a small negative risk aversion coefficient that approaches 0 , the spread above is:

$$
r_{2}^{2}-\left(r_{1}(1-t)\right)^{2}=R-\left[\frac{R}{A}\right]^{2}
$$

Since $A=R / r_{1}$ * in the case of $t=0$ and since $A$ is increasing in the tax, this spread is always positive.

QED

In the case a tax is imposed, constraint C.3, "expect to stay in" must be >0:

$$
\mathrm{C} 3=\frac{\varepsilon}{\gamma}\left(\mathrm{r}_{1}(1-\mathrm{t})\right)^{\gamma}+\frac{(1-\varepsilon)}{\gamma}\left(\mathrm{r}_{2}^{2}\right)^{\gamma}-\frac{\varepsilon}{\gamma}\left(\mathrm{r}_{1}(1-\mathrm{t})\right)^{\gamma}-\frac{(1-\varepsilon)}{\gamma}\left(\mathrm{r}_{1}(1-\mathrm{t}) \mathrm{r}_{2}^{*}\right)^{\gamma}
$$

Simplify and insert equilibrium contract values, equations (A.20) and (8'), where the latter is multiplied by (1-t):

$$
\frac{(1-\varepsilon)}{\gamma}\left[\frac{\mathrm{R}}{\varepsilon \mathrm{A}^{\frac{\gamma}{(\gamma-1)}}+(1-\varepsilon)}\right]^{\gamma}-\frac{(1-\varepsilon) \mathrm{r}_{2}^{* \gamma}}{\gamma}\left[\frac{\mathrm{R}}{\mathrm{A}\left(\varepsilon+(1-\varepsilon) \mathrm{A}^{\frac{\gamma}{(1-\gamma)}}\right)}\right]^{\gamma}
$$

where $\mathrm{A}$ is defined as above. Factor $\mathrm{R}^{\gamma}$ and prepare to combine terms:

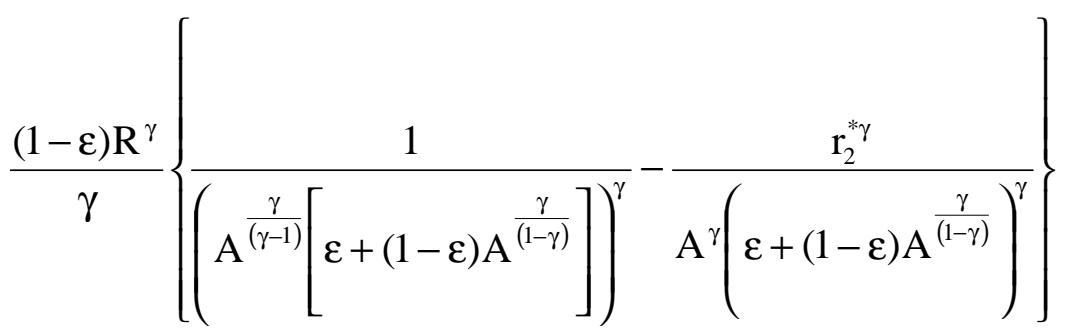


Factor the A term and combine. For constraint C.3 to be satisfied the following must be true:

$$
\frac{(1-\varepsilon) \mathrm{R}^{\gamma}}{\gamma \mathrm{A}^{\frac{\gamma^{2}}{(\gamma-1)}}}\left\{\frac{1-\mathrm{r}_{2}^{* \gamma} \mathrm{A}^{\frac{\gamma}{(\gamma-1)}}}{\left(\varepsilon+(1-\varepsilon) \mathrm{A}^{\frac{\gamma}{(1-\gamma)}}\right)^{\gamma}}\right\}>0
$$

For the important case when $\gamma<0$, the numerator must be negative. Decomposing A, that means:

$$
\left((1-t) r_{1}^{*}\right)^{\frac{\gamma}{(\gamma-1)}}<r_{2}^{*} \gamma\left(R-r_{1}^{*} r_{2}^{*} t\right) \frac{\gamma}{(\gamma-1)}
$$

Take the root of both sides and solve for $\mathrm{r}_{1}{ }^{*}$

$$
\mathrm{r}_{1}^{*}\left(\left(1-\mathrm{t}\left(1-\mathrm{r}_{2}^{* \gamma}\right)\right)<\mathrm{r}_{2}^{*(\gamma-1)} \mathrm{R}\right.
$$

Dividing both sides by : $\quad r_{2}^{*(\gamma-1)}\left(\left(1-t\left(1-r_{2}^{* \gamma}\right)\right)\right.$, we obtain:

$$
\mathrm{r}_{1}^{*} \mathrm{r}_{2}^{*(1-\gamma)}<\frac{\mathrm{R}}{\left(\left(1-\mathrm{t}\left(1-\mathrm{r}_{2}^{*}\right)\right)\right.}
$$

This is true by assumption A.2

QED. 